\title{
Multitemporal Soil Moisture Retrieval over Bare Agricultural Areas by Means of Alpha Model with Multisensor SAR Data
}

\author{
Xiang Zhang $\mathbb{C D}^{1}{ }^{1}$ Xinming Tang, ${ }^{1}$ Xiaoming Gao, ${ }^{1}$ and Hui Zhao ${ }^{2}$ \\ ${ }^{1}$ Satellite Surveying and Mapping Application Center, National Administration of Surveying, \\ Mapping and Geo-information, Beijing 100048, China \\ ${ }^{2}$ National Geomatics Center of China, Beijing 100080, China \\ Correspondence should be addressed to Xiang Zhang; zhangxiangcumt@126.com
}

Received 25 January 2018; Revised 6 April 2018; Accepted 30 April 2018; Published 23 May 2018

Academic Editor: Qingyan Meng

Copyright ( 12018 Xiang Zhang et al. This is an open access article distributed under the Creative Commons Attribution License, which permits unrestricted use, distribution, and reproduction in any medium, provided the original work is properly cited.

\begin{abstract}
The objective of this research is to optimize the Alpha approximation model for soil moisture retrieval using multitemporal SAR data. The Alpha model requires prior knowledge of soil moisture range to constrain soil moisture estimation. The solution of the Alpha model is an undetermined problem due to the fact that the number of observation equations is less than the number of unknown parameters. This research primarily focused on the optimization of Alpha model by employing multisensor and multitemporal SAR data. The disadvantage of the Alpha model can be eliminated by the combination of multisensor SAR data. The optimized Alpha model was evaluated on the basis of a comprehensive campaign for soil moisture retrieval, which acquired multisensor time series SAR data and coincident field measurements. The agreement between the estimated and measured soil moisture was within a root mean square error of $0.08 \mathrm{~cm}^{3} / \mathrm{cm}^{3}$ for both methods. The optimized Alpha model shows an obvious improvement for soil moisture retrieval. The results demonstrated that multisensor and multitemporal SAR data are favorable for time series soil moisture retrieval over bare agricultural areas.
\end{abstract}

\section{Introduction}

Soil moisture is an essential parameter controlling many biophysical processes that impact water, energy, and carbon exchanges at the land-atmosphere interface. Synthetic aperture radar (SAR) is one of the most promising techniques for measuring surface soil moisture at moderate-to-high spatial resolution required by hydrological, meteorological, ecological, and agricultural applications [1-3]. However, accurate soil moisture retrieval from SAR data is still a challenging task due to the fact that the radar backscatter is influenced by multiple parameters such as soil dielectric constant (related to soil moisture), surface roughness, and vegetation conditions [4-10]. Therefore, soil moisture retrieval from SAR data is an ill-posed problem, and thus, it requires either prior knowledge of vegetation and soil surface parameters or multiple configuration SAR data. The multitemporal [11, 12], multi-incidence angle [13-15], multipolarization [16-19], and multifrequency [20] SAR data are increasingly applied for soil moisture retrieval to avoid using less observations than the number of unknown parameters [21, 22].

The availability of SAR data characterized by short repeating cycles such as Radarsat-2, Sentinel-1, ALOS-2, Cosmo-SkyMed, and TerraSAR-X/TanDEM-X provides possible alternatives for monitoring soil moisture change at fine spatial scales through change detection methods [23]. The rationale of such approach is that temporal changes of surface roughness and vegetation take place at longer temporal scales than soil moisture changes [24-27]. Therefore, time series SAR data acquired with short repeat cycles are expected to obtain the soil moisture change. A change detection method referred to as the Alpha approximation model was initially developed under a simplified theoretical assumption [28], being that the ratio of two consecutive backscatter measurements could be approximately represented as the squared ratio of corresponding Alpha coefficients. The Alpha approximation model has 
been tested using different SAR datasets with different radar frequencies [29-32].

The Alpha approximation model is appealing for soil moisture retrieval due to its simplicity, and this method requires the initial estimates of soil moisture boundary. Such bounds can be obtained from climate models, calibration on a specific dataset [31-34], or juxtaposition method [35, 36]. Furthermore, the system of equations constructed using the Alpha model has more unknowns than equations; thus, there exist an infinite number of solutions. Therefore, these issues hampered the accurate estimation of soil moisture content using the Alpha model.

This paper aims at developing an optimized Alpha model by transforming the original underdetermined system of the Alpha approximation model into an overdetermined system. The contribution is an extension of the Alpha model to multisensor configurations. With the application of time series Radarsat-2 and Sentinel-1A SAR data, the number of the observation equations is more than the number of unknown parameters. Thus, the comprehensive cost function can be structured to estimate the optimized soil moisture content within a valid bound. The developed approach was quantitatively evaluated according to the field soil moisture measurements over Hebei agricultural areas.

This paper is organized as follows. Section 2 introduces the comprehensive soil moisture retrieval campaign, including the experimental area, acquisitions of multisensor time series SAR data, and continuous field measurements. Section 3 provides an overview of the Alpha approximation model and its extension to multisensor configurations. Section 4 firstly evaluates the Alpha approximation model based on the forward scattering model and time series SAR data. Then, the comparison between the Alpha approximation model and the developed method is implemented, and the results are further analyzed and discussed. Section 5 presents the conclusions and discusses potential future applications.

\section{Study Area and Datasets}

From Oct. 2015 to Mar. 2016, a comprehensive scientific campaign for soil moisture retrieval was implemented over Hebei agricultural areas. The campaign encompassed multisensor time series spaceborne SAR acquisitions and continuous field measurements for vegetation and soil surface parameters during 13 Oct. 2015 to 5 Mar. 2016.

2.1. Study Area. The agricultural area chosen for this study is part of the North China Plain located in the south of Hebei, China $\left(114^{\circ} 5^{\prime}-114^{\circ} 35^{\prime} \mathrm{E}, 36^{\circ} 25^{\prime}-36^{\circ} 55^{\prime} \mathrm{N}\right)$. Field measurements were implemented over the JiuLong $\left(114^{\circ} 10^{\prime}-114^{\circ} 20^{\prime} \mathrm{E}\right.$, $\left.36^{\circ} 25^{\prime}-36^{\circ} 35^{\prime} \mathrm{N}\right)$ and WanNian $\left(114^{\circ} 5^{\prime}-114^{\circ} 15^{\prime} \mathrm{E}, 36^{\circ} 35^{\prime}-\right.$ $36^{\circ} 45^{\prime} \mathrm{N}$ ) experimental areas, as shown in Figure 1. The topography of the experimental area is relatively flat. The soil texture is dominantly characterized as loam soil, and the sand and clay proportions are approximate $50 \%$ and $15 \%$, respectively. The main crops are wheat and corn over the study area.

Since Oct 2015, the dominated crop corn has been totally harvested over the study area. Partial of the agricultural areas

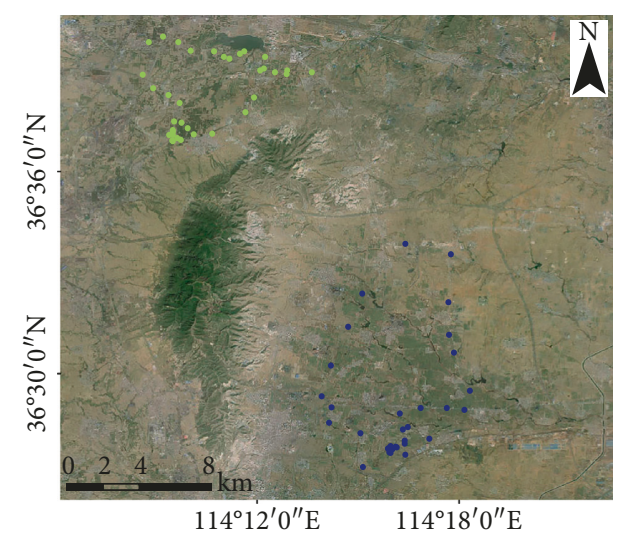

FIgURE 1: Study area and sampling sites. The upper left and lower right represent the WanNian and JiuLong experimental areas, respectively. The round dots indicate the sampling sites.

were seeded with winter wheat, and partial of the agricultural areas were languished. From Oct. 2015 to Mar. 2016, the study area was mainly characterized by bare soil or sparse winter wheat. During this period, the temperature is relatively low, and thus, the winter wheat grows slowly and the biomass retains a relatively low level (less than $0.5 \mathrm{~kg} / \mathrm{m}^{2}$ ). Figure 2 shows the different winter wheat growth stages from 13 Oct. 2015 to 5 Mar. 2016. Therefore, the study area can be considered as bare soil surfaces, and the influence of winter wheat to backscattering coefficients can be ignored [1]. In addition, there is no agricultural activity over the study area during this period, the soil surface roughness can be considered as constant, and thus, it is suitable for the application of change detection methods.

2.2. SAR Data. Time series Radarsat-2, TerraSAR-X, and Sentinel-1A images were acquired, and continuous field measurements were implemented over the study area. The time interval among TerraSAR-X acquisitions and other SAR data acquisitions is long; thus, only the time series Radarsat-2 and Sentinel-1A data were selected as experimental dataset. Table 1 lists the configuration parameters and acquisition time of multisensor SAR data.

During the scientific campaign, a total of five Radarsat-2 and three Sentinel-1A images were acquired from Oct. 2015 to Mar. 2016. To transfer the intensity to backscattering coefficients, a standard preprocessing phase is performed. The entire process, including the speckle filter, radiometric correction, and range-Doppler terrain correction, is conducted using the NEST and SNAP software provided by ESA. First, the images are filtered using the Lee filter with a $5 \times 5$ window size [37]. Radiometric calibrations are then conducted to derive the backscattering coefficients. Finally, the images are georeferenced using SRTM as an external DEM. Considering the different spatial resolutions of Radarsat-2 and Sentinel-1A images, the resampling process was conducted to obtain the same spatial resolution. Table 2 lists the time of SAR data acquisitions and field measurements.

During two days interval of Radarsat- 2 and Sentinel-1A acquisitions, there was no precipitation, large temperature 


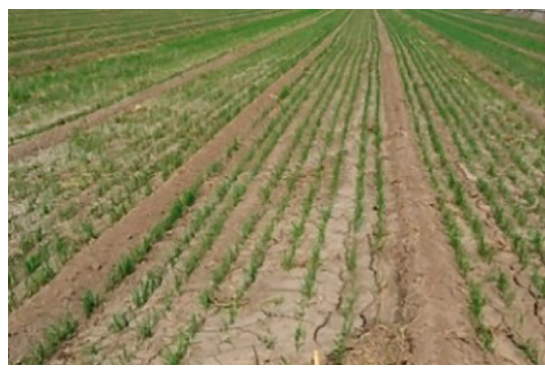

(a)

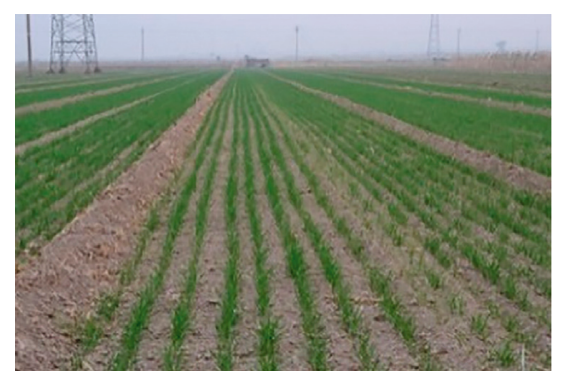

(b)

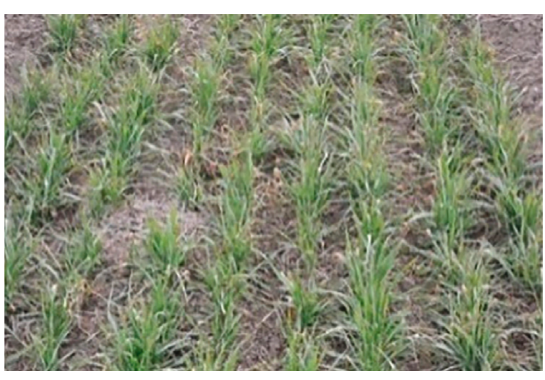

(c)

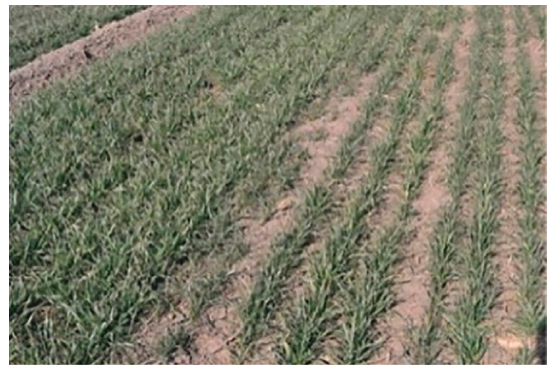

(d)

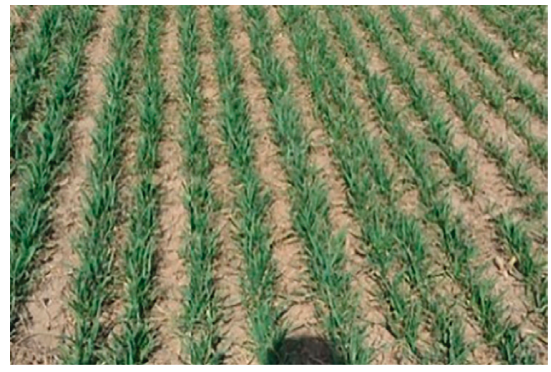

(e)

Figure 2: Wheat growth stage in Hebei study area from Oct. 2015 to Mar. 2016. (a) 13 Oct. 2015, (b) 6 Nov. 2015, (c) 24 Dec. 2015 , (d) 17 Jan. 2016, and (e) 5 Mar. 2016.

TABLE 1: Configuration parameters and acquisition time of multisensor SAR data.

\begin{tabular}{|c|c|c|c|c|c|c|c|}
\hline SAR data & $\begin{array}{c}\text { Acquisition } \\
\text { date }\end{array}$ & $\begin{array}{c}\text { Band } \\
\text { frequency }\end{array}$ & Polarization & $\begin{array}{c}\text { Incidence } \\
\text { angle }\end{array}$ & Imaging mode & Resolution & $\begin{array}{l}\text { Revisit } \\
\text { period }\end{array}$ \\
\hline $\mathrm{ac}$ & ct. 20 & C $5.4 \mathrm{GHz}$ & $\mathrm{H}$ & $36^{\circ}$ & & & 24 days \\
\hline Sentinel-1A & Oct. 2015 to Mar. 2016 & C $5.4 \mathrm{GHz}$ & $\mathrm{VV} / \mathrm{VH}$ & $38^{\circ}$ & Interferometric wide swath & $20 \mathrm{~m}$ & 12 days \\
\hline
\end{tabular}

TABLE 2: Time of SAR data acquisitions and field measurements.

\begin{tabular}{lccc}
\hline $\begin{array}{l}\text { Acquisition } \\
\text { time }\end{array}$ & Radarsat-2 & Sentinel-1A & $\begin{array}{c}\text { Field } \\
\text { measurements }\end{array}$ \\
\hline$T_{1}$ & 13 Oct. 2015 & 15 Oct. 2015 & 13 Oct. 2015 \\
$T_{2}$ & 6 Nov. 2015 & - & 6 Nov. 2015 \\
$T_{3}$ & 24 Dec. 2015 & 26 Dec. 2015 & 24 Dec. 2015 \\
$T_{4}$ & 17 Jan. 2016 & - & 17 Jan. 2016 \\
$T_{5}$ & 5 Mar. 2016 & 7 Mar. 2016 & 5 Mar. 2016 \\
\hline
\end{tabular}

variation, and agricultural activity over the experimental areas. Therefore, the soil moisture and surface roughness are considered to be constant between each of the multisensor SAR data acquisitions, which provide the potential of multisensor SAR for soil moisture retrieval.

2.3. Field Measurements. Simultaneously with Radarsat-2 acquisitions, continuous field measurements were implemented over the study area. Different sampling sites were selected over JiuLong and WanNian experimental areas, respectively. Soil surface parameters were measured, including volumetric soil moisture content $(0-5 \mathrm{~cm})$ and surface roughness parameters. For each sampling site, three sample points were selected as representatives within an area of $30 \mathrm{~m} \times 30 \mathrm{~m}$. The distance between the sample points is approximately ten meters. Soil moisture content was collected by a calibrated TDR (time domain reflectometry) probe, and the measured soil moisture was calibrated on the basis of gravimetric method.

Soil moisture content of each sampling site was obtained by the average of three sample measurements. Over the JiuLong experimental area, the soil moisture content varied from 0.03 to $0.46 \mathrm{~cm}^{3} / \mathrm{cm}^{3}$, and the soil moisture ranged from 0.06 to $0.51 \mathrm{~cm}^{3} / \mathrm{cm}^{3}$ over the WanNian experimental area. A portable global positioning system (GPS) was used to identify and register the sampling positions with one meter accuracy. The surface roughness was measured using a needle profilometer with a length of one meter $(2 \mathrm{~cm}$ sampling interval). At each sample point, four surface profiles (two parallel and two perpendicular to the row direction) were recorded. These profiles were photographed and then digitized. The root mean square height $(h)$ and correlation length $(l)$ were calculated using a MATLAB program [38]. The value of $h$ varied from 0.51 to $1.79 \mathrm{~cm}$ over the JiuLong experimental area, while in WanNian experimental area, $h$ changed from 0.50 to $1.90 \mathrm{~cm}$. The value of $l$ varied from 5.2 to $21.6 \mathrm{~cm}$ over the JiuLong experimental area, while in WanNian experimental area, $l$ changed from 6.1 to $23.1 \mathrm{~cm}$. Furthermore, considering the presence of positioning errors, geographical registration between SAR data and field measurement sites was implemented based on ten corner reflectors located in the experimental areas. The field measurements collected from the experimental areas 
TABLE 3: The statistics results of the field measurements over the study area.

\begin{tabular}{lccccccccccc}
\hline \multirow{2}{*}{$\begin{array}{l}\text { Field } \\
\text { measurement }\end{array}$} & $\begin{array}{c}\text { Experimental } \\
\text { area }\end{array}$ & $\begin{array}{c}\text { Sampling } \\
\text { number }\end{array}$ & \multicolumn{2}{c}{ Soil moisture $\left(\mathrm{cm}^{3} / \mathrm{cm}^{3}\right)$} & \multicolumn{3}{c}{$h(\mathrm{~cm})$} & \multicolumn{2}{c}{$l(\mathrm{~cm})$} \\
\multirow{2}{*}{ 13 Oct. 2015 } & Min & Max & Average & Min & Max & Average & Min & Max & Average \\
& JiuLong & 27 & 0.03 & 0.345 & 0.116 & 0.51 & 1.79 & 1.13 & 7.3 & 20.2 & 15.1 \\
& WanNian & 26 & 0.06 & 0.307 & 0.15 & 0.50 & 1.88 & 1.12 & 7.6 & 21.8 & 16.3 \\
\hline \multirow{2}{*}{ 6 Nov. 2015 } & JiuLong & 21 & 0.249 & 0.427 & 0.34 & 0.61 & 1.67 & 1.07 & 5.6 & 17.7 & 13.6 \\
& WanNian & 23 & 0.224 & 0.508 & 0.297 & 0.57 & 1.73 & 1.11 & 6.7 & 19.7 & 15.4 \\
\hline \multirow{2}{*}{ 24 Dec. 2015 } & JiuLong & 30 & 0.15 & 0.464 & 0.243 & 0.54 & 1.77 & 1.09 & 7.7 & 18.5 & 14.3 \\
& WanNian & 27 & 0.13 & 0.421 & 0.194 & 0.60 & 1.90 & 1.17 & 8.3 & 21.9 & 16.7 \\
\hline \multirow{2}{*}{ 17 Jan. 2016 } & JiuLong & 30 & 0.118 & 0.322 & 0.193 & 0.66 & 1.64 & 1.03 & 5.2 & 18.9 & 15.3 \\
& WanNian & 30 & 0.11 & 0.452 & 0.202 & 0.59 & 1.78 & 1.13 & 7.9 & 23.1 & 17.6 \\
\hline \multirow{2}{*}{ 5 Mar. 2016 } & JiuLong & 30 & 0.067 & 0.46 & 0.176 & 0.63 & 1.73 & 1.17 & 6.4 & 21.6 & 16.1 \\
& WanNian & 30 & 0.06 & 0.29 & 0.147 & 0.60 & 1.71 & 1.11 & 6.1 & 22.3 & 16.8 \\
\hline
\end{tabular}

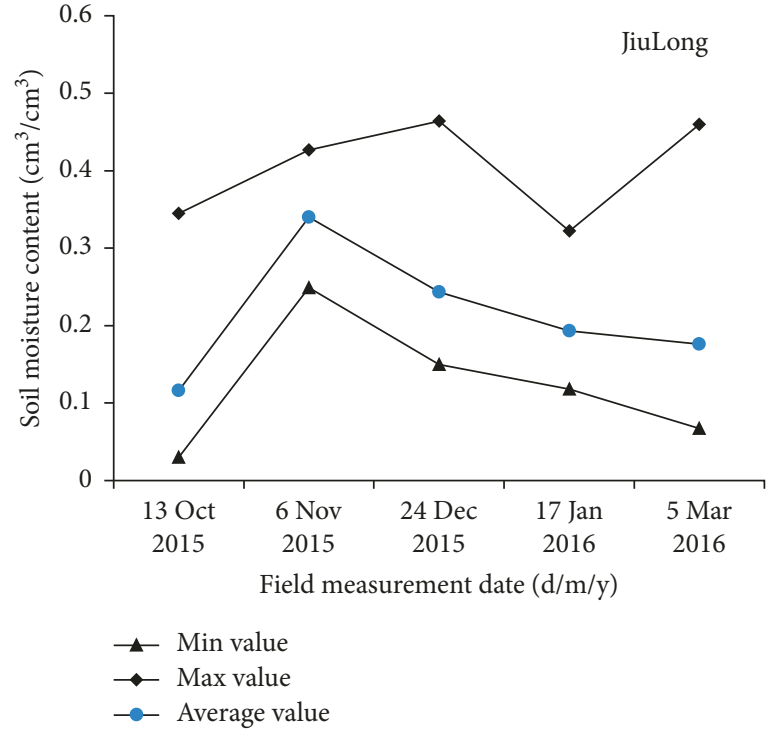

(a)

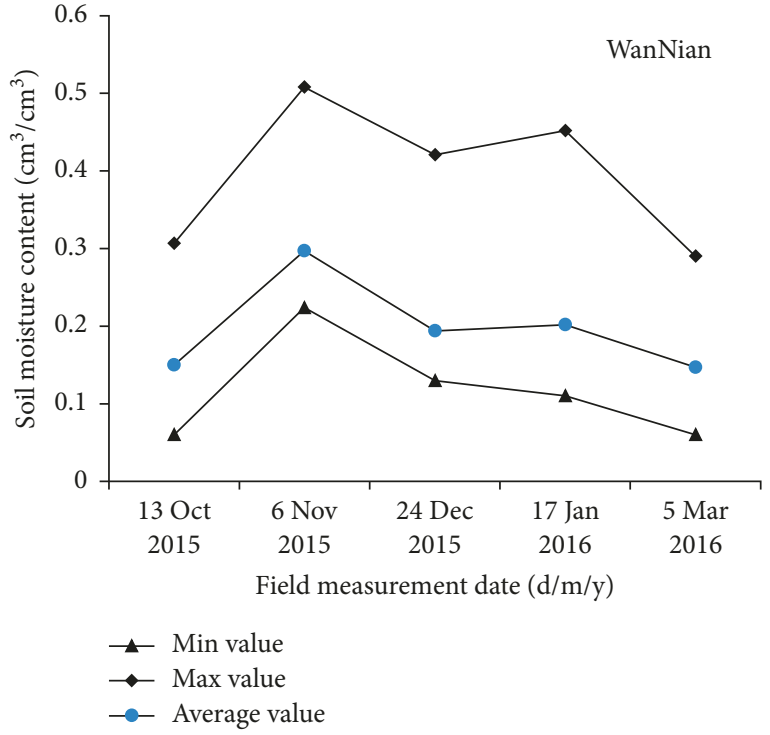

(b)

Figure 3: Statistics graphs of the time series soil moisture measurements. (a) JiuLong experimental area. (b) WanNian experimental area.

allow for the validation of feasibility and effectiveness of the developed soil moisture retrieval method. Table 3 lists the statistic results of the time series field measurements over JiuLong and WanNian experimental areas.

For time series soil moisture measurements, the minimum, maximum, and average values of soil moisture content were graphed as Figure 3.

There is obvious precipitation on 5 Nov. 2015 over the study area. Thus, the average soil moisture content measured on 6 Nov. 2015 is higher than the other field measurements. There is no agricultural activity during Oct. 2015 to Mar. 2016 over the study area, and the soil surface roughness shows relatively stable for the continuous field measurements. Therefore, the assumptions of the change detection methods are fulfilled. Figure 4 shows part of the field photos for in situ measurements over the study area.

\section{Methodologies}

3.1. Overview of the Alpha Model. Soil surface roughness has significant influence on the backscattering coefficient. For soil moisture retrieval, surface roughness can be considered as noise; thus, it is essential to eliminate the noise to obtain reliable soil moisture retrievals. Generally, soil surface roughness is more stable than soil moisture. The variation of soil surface roughness is originated from the seasonal agricultural activities over the agricultural areas. Therefore, soil surface roughness can be considered as constant during a certain period, and soil moisture change is the crucial factor for the variation of backscattering coefficients for bare soil surfaces. Based on the abovementioned theory and assumption, the application of multitemporal SAR data can effectively remove the influence of surface roughness, thus to obtain accurate soil moisture content. Therefore, the change detection methods for soil moisture retrieval have been widely developed.

Balenzano et al. proposed the Alpha approximation approach for soil moisture retrieval from multitemporal SAR data [28]. When time series SAR measurements are available for bare soil surface, assuming no variation of surface roughness during SAR acquisitions, the backscatter change is related to soil moisture change only. Furthermore, 

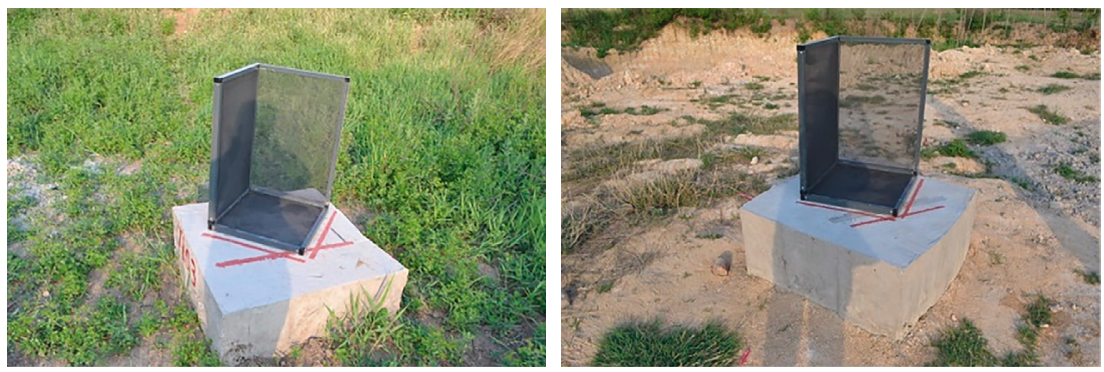

(a)
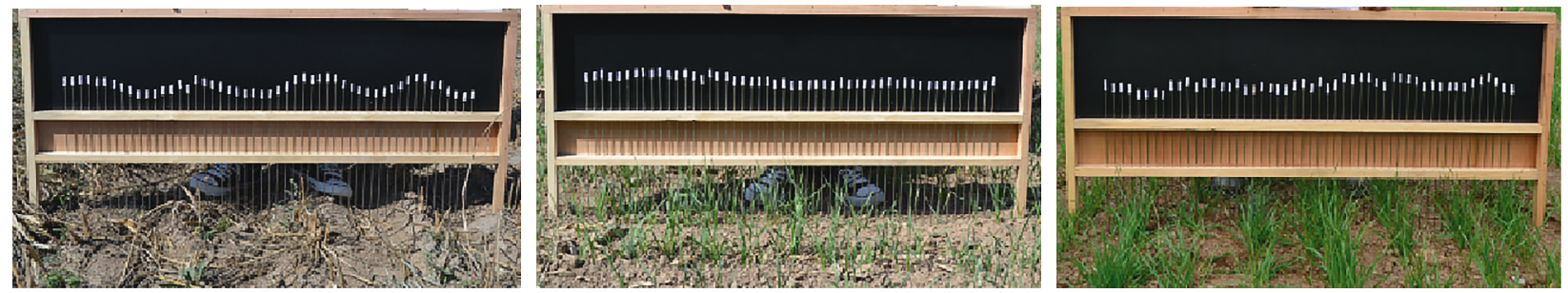

(b)

Figure 4: Field photos of the in situ measurements over the study area. (a) Corner reflectors. (b) Surface roughness measurements.

the ratio of two consecutive backscatter measurements can be approximately represented as the squared ratio of corresponding Alpha coefficients [28].

$$
\frac{\sigma_{\mathrm{pp}}^{T_{2}}}{\sigma_{\mathrm{pp}}^{T_{1}}} \approx\left|\frac{\alpha_{\mathrm{pp}}^{T_{2}}(\varepsilon, \theta)}{\alpha_{\mathrm{pp}}^{T_{1}}(\varepsilon, \theta)}\right|^{2},
$$

where $\sigma$ is the backscattering coefficient represented as intensity, $\theta$ is the incidence angle, $\varepsilon$ is the soil dielectric constant, pp denotes the polarization mode (i.e., $\mathrm{HH}$ or $\mathrm{VV}$ ), and $T_{1}$ and $T_{2}$ represent the acquisition time of multitemporal SAR data. The Alpha coefficient $\alpha_{\mathrm{pp}}$ is a function of dielectric constant $\varepsilon$ and incidence angle $\theta$, and it is given by [39]

$$
\begin{aligned}
& \left|\alpha_{\mathrm{HH}}(\varepsilon, \theta)\right|=\left|\frac{(\varepsilon-1)}{\left(\cos \theta+\sqrt{\varepsilon-\sin ^{2} \theta}\right)^{2}}\right|, \\
& \left|\alpha_{\mathrm{VV}}(\varepsilon, \theta)\right|=\left|\frac{(\varepsilon-1)\left(\sin ^{2} \theta-\varepsilon\left(1+\sin ^{2} \theta\right)\right)}{\left(\varepsilon \cos \theta+\sqrt{\varepsilon-\sin ^{2} \theta}\right)^{2}}\right| .
\end{aligned}
$$

According to $T_{1}$ and $T_{2}$ SAR acquisitions, the observation equation can be established based on (1).

$$
\left|\alpha_{\mathrm{pp}}^{T_{1}}(\varepsilon, \theta)\right|-\sqrt{\frac{\sigma_{\mathrm{pp}}^{T_{1}}}{\sigma_{\mathrm{pp}}}} \cdot\left|\alpha_{p p}^{T_{2}}(\varepsilon, \theta)\right|=0 .
$$

For the consecutive $N$ SAR acquisitions, the number of the observation equations can reach to $N \times(N-1) / 2$. Due to the ratio relationship between different temporal SAR data, there is redundancy among these observation equations. Therefore, based on the N SAR acquisitions, the number of the effective observation equations is $N-1$. In order to maintain the soil surface roughness to be constant between different temporal SAR acquisitions, the adjacent SAR acquisitions $\left(T_{N-1}\right.$ and $\left.T_{N}\right)$ were utilized to structure the observation equations. Therefore, the observation equations of the Alpha model can be expressed as follows:

$$
\left[\begin{array}{ccccccc}
1 & -\sqrt{\frac{\sigma_{\mathrm{pp}}^{T_{1}}}{\sigma_{\mathrm{pp}}}} & 0 & 0 & \cdots & 0 & 0 \\
0 & 1 & -\sqrt{\frac{\sigma_{\mathrm{pp}}^{T_{2}}}{\sigma_{\mathrm{pp}}^{2}}} & 0 & \cdots & 0 & 0 \\
\cdots & \cdots & \cdots & \cdots & \cdots & \cdots & \cdots \\
\cdots & \cdots & \cdots & \cdots & \cdots & 1 & -\sqrt{\frac{\sigma_{\mathrm{pp}}^{T_{N-1}}}{\sigma_{\mathrm{pp}}^{T_{N}}}}
\end{array}\right]
$$

$$
\left[\begin{array}{c}
\left|\alpha_{\mathrm{pp}}^{T_{1}}(\varepsilon, \theta)\right| \\
\left|\alpha_{\mathrm{pp}}^{T_{2}}(\varepsilon, \theta)\right| \\
\cdots \\
\left|\alpha_{\mathrm{pp}}^{T_{N}}(\varepsilon, \theta)\right|
\end{array}\right]=\left[\begin{array}{c}
0 \\
0 \\
\cdots \\
0
\end{array}\right] .
$$

If the ratios between consecutive backscatter values are considered according to (1), N SAR acquisitions result in $(N-1)$ observation equations and $N$ unknown dielectric constants (for single polarization case), leading to a system of equations having more unknowns than equations. To solve this underdetermined system of equations, the bounded least-squares optimization is applied [28] to estimate the dielectric constant values. In the case where multitemporal SAR data are used, the Alpha coefficients can be derived in a least-squares sense. Thus, the soil moisture content can be derived on the basis of the dielectric mixing model [40]. 
3.2. Developed Alpha Model. The system of equations constructed using (1) has more unknowns than the number of equations, and thus there exist infinite number of solutions. In this paper, the multisensor SAR data are employed to solve the underdetermined system of equations. The original underdetermined solution was transformed into the solution of overdetermined equation. A technique by minimizing the comprehensive cost function was employed to obtain the optimized soil dielectric constant. During this processing, soil dielectric constant bounds should be given according to the field measurements. The consecutive field measurement of soil moisture content is within $0.03 \mathrm{~cm}^{3} / \mathrm{cm}^{3}$ and $0.51 \mathrm{~cm}^{3} / \mathrm{cm}^{3}$. Thus, the solution of dielectric constant can be restricted in a valid bound [40]. The retrieval schemes of the developed Alpha model are detailed in the following sections.

Firstly, time series Radarsat-2 SAR data with $\mathrm{HH}$ polarization can be used to establish the independent observation equations.

$$
\begin{aligned}
& {\left[\begin{array}{ccccc}
1 & -\sqrt{\frac{\sigma_{\text {hhR2 }}^{T_{1}}}{\sigma_{\text {hhR2 }}}} & 0 & 0 & 0 \\
0 & 1 & -\sqrt{\frac{\sigma_{\mathrm{hhR} 2}^{T_{2}}}{\sigma_{\mathrm{hhR} 2}^{T_{3}}}} & 0 & 0 \\
0 & 0 & 1 & -\sqrt{\frac{\sigma_{\mathrm{hhR2}}^{T_{3}}}{\sigma_{\mathrm{hhR2}}}} & 0 \\
0 & 0 & 0 & 1 & -\sqrt{\frac{\sigma_{\mathrm{hhR} 2}^{T_{4}}}{\sigma_{\mathrm{hhR} 2}}}
\end{array}\right]}
\end{aligned}
$$

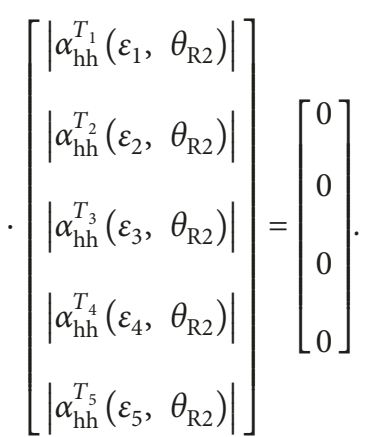

According to the observation equations established by the multitemporal Radarsat- 2 data, the estimation of soil moisture content is an underdetermined solution in combination with the effective range of soil moisture content. Accounting for the ill-posed problem, the optimized Alpha model combining the multisensor SAR data was developed to overcome the uncertainty of the estimated results.

The multisensor time series SAR data are utilized to estimate the soil moisture content by means of the Alpha model. The time series Radarsat-2 and Sentinel-1A SAR data are respectively employed to construct the observation equations, which transform the underdetermined solution into overdetermined solution. Thus, the multiple solutions of soil moisture content can be constrained to the unique solution. Therefore, the uncertainty of the estimated soil moisture was significantly reduced.

The time series Sentinel-1A SAR data with VV polarization can be utilized to construct the following observation equations.

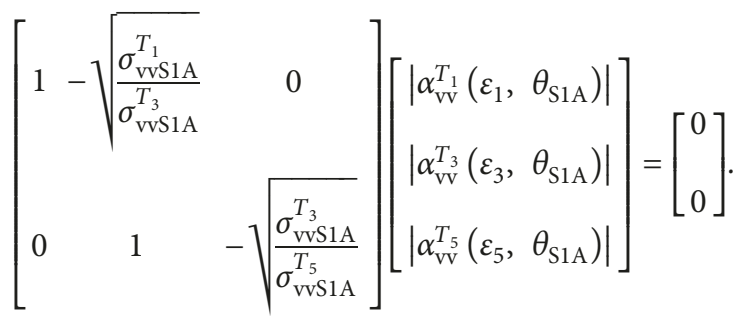

Therefore, the integrated observation equations can be structured in combination with multitemporal Radarsat-2 and Sentinel-1A data.

$$
\left[\begin{array}{cc}
M_{\mathrm{hhR} 2} & M_{\mathrm{o}} \\
M_{\mathrm{o}} & M_{\mathrm{vvS} 1 \mathrm{~A}}
\end{array}\right]\left[\begin{array}{c}
\alpha_{\mathrm{hhR2}} \\
\alpha_{\mathrm{vvS} 1 \mathrm{~A}}
\end{array}\right]=\left[\begin{array}{l}
0 \\
0
\end{array}\right],
$$

where $M_{\mathrm{hhR} 2}$ and $M_{\mathrm{vvS} 1 \mathrm{~A}}$ are the coefficient matrixes of (5) and (6), derived from time series Radarsat-2 and Sentinel-1A data respectively. $\alpha_{\mathrm{hhR2}}$ and $\alpha_{\mathrm{vvS} 1 \mathrm{~A}}$ are the Alpha coefficient corresponding to $\mathrm{HH}$ and VV polarization, respectively.

For the above observation equations, the unknown parameters $\left|\alpha_{\mathrm{pp}}^{T_{N}}(\varepsilon, \theta)\right|$ just depend on the soil dielectric constant and incidence angle. For the approximately simultaneous acquisitions of multisensor SAR data, the soil dielectric constant is equivalent, and the incidence angle is a known parameter. Therefore, there are five unknown dielectric constants in observation (7). The original underdetermined system was transformed into an overdetermined system. Thus, the unique solution of soil moisture can be obtained with multisensor time series SAR data as inputs.

The observation (7) constructed by multitemporal Radarsat-2 and Sentinel-1A data can be expressed as $M_{\mathrm{hhR} 2} \alpha_{\mathrm{hhR} 2}=0$ and $M_{\mathrm{vvS} 1 \mathrm{~A}} \alpha_{\mathrm{vvS} 1 \mathrm{~A}}=0$. Thus, the target function of optimal solution can be obtained by combining the time series Radarsat-2 and Sentinel-1A data. According to the above analysis, the comprehensive cost function can be expressed as

$$
\Delta=\min \sqrt{\left(M_{\mathrm{hhR} 2} \alpha_{\mathrm{hhR} 2}\right)^{2}+\left(M_{\mathrm{vvS} 1 \mathrm{~A}} \alpha_{\mathrm{vvS} 1 \mathrm{~A}}\right)^{2}} .
$$

This expression not only contains the constraint of time series Radarsat- 2 data but also is constrained by time series Sentinel-1A data. Based on the given range of soil moisture content, the numerical solution of soil moisture can be obtained by minimizing the comprehensive cost function.

\section{Results and Discussions}

Firstly, the rationality of Alpha model was evaluated on the basis of IEM (integral equation model) and Oh model within a wide range of soil surface parameters. Then, the applicability of Alpha model was further assessed in combination 
with time series SAR data and field measurements. The multitemporal Radarsat- 2 data and measured soil moisture of the same sampling sites were employed for the theoretical analysis.

After the evaluation and validation for the forward model, the Alpha approximation method was applied for soil moisture retrieval over the experimental areas. Firstly, the observation equations based on the Alpha model were constructed using multitemporal Radarsat-2 data. Then, soil moisture was estimated in combination with the valid range of soil moisture content. Against the shortcoming of the underdetermined system, the application of multisensor SAR data was developed to transform the underdetermined system into an overdetermined system by providing independent observation equations.

\subsection{Alpha Model Evaluation}

4.1.1. Alpha Model Evaluation Based on the Oh and IEM Simulation Data. Oh [16] and IEM [41] simulation data were utilized to evaluate the rationality of Alpha model. The input parameters of radar backscattering model include the soil dielectric constant (related to soil moisture content), root mean square height, correlation length, incidence angle, and radar wavelength, which can be determined according to the field measurements and SAR configuration parameters. The configuration parameters (incidence angle, radar wavelength, and polarization) of Radarsat- 2 and Sentinel-1A images were used as inputs for $\mathrm{Oh}$ and IEM simulation. Soil surface root mean square height changes from $0.1 \mathrm{~cm}$ to $2.0 \mathrm{~cm}$ with an interval of $0.1 \mathrm{~cm}$, and correlation length varies from $1 \mathrm{~cm}$ to $20 \mathrm{~cm}$ with an interval of $1 \mathrm{~cm}$. Backscattering coefficients were simulated based on the Oh and IEM model with different soil moisture contents as inputs. Thus, the time series backscattering coefficients can be obtained corresponding to the same soil roughness parameters and different soil moisture contents. The relationship between the ratio of backscattering coefficients $\sigma_{\mathrm{pp}}^{T_{2}} / \sigma_{\mathrm{pp}}^{T_{1}}$ and squared ratio of Alpha coefficients $\left|\alpha_{\mathrm{pp}}^{T_{2}} / \alpha_{\mathrm{pp}}^{T_{1}}\right|^{2}$ were quantitatively assessed. Figure 5 shows the relationship between $\left|\alpha_{\mathrm{pp}}^{T_{2}} / \alpha_{\mathrm{pp}}^{T_{1}}\right|^{2}$ and $\sigma_{\mathrm{pp}}^{T_{2}} / \sigma_{\mathrm{pp}}^{T_{1}}$ simulated by the IEM and Oh model, respectively.

The simulation results show good agreement between the squared ratio of Alpha coefficients and the ratio of backscattering coefficients simulated by IEM for $\mathrm{HH}$ and $\mathrm{VV}$ polarization. And, good correlation between $\left|\alpha_{\mathrm{pp}}^{T_{2}} / \alpha_{\mathrm{pp}}^{T_{1}}\right|^{2}$ and $\sigma_{\mathrm{pp}}^{T_{2}} / \sigma_{\mathrm{pp}}^{T_{1}}$ was obtained for the Oh model. The aforementioned results theoretically demonstrated the rationality of Alpha model. The influence of surface roughness can be effectively eliminated by the ratio model. Therefore, the relationship between the ratio of backscattering coefficients and the squared ratio of Alpha coefficients can be structured to estimate the soil moisture content using time series SAR data.

4.1.2. Alpha Model Evaluation Based on Multitemporal Radarsat-2 Data and Field Measurements. Time series Radarsat-2 data and measured soil moisture were employed to further evaluate the availability of Alpha model. The following acquisitions of SAR data and measured soil moisture were utilized over JiuLong and WanNian experimental areas, including 24 Dec. 2015, 17 Jan. 2016, and 5 Mar. 2016. Figure 6 shows the relationship between the ratio of time series backscattering coefficients and the squared ratio of Alpha coefficients derived from measured soil moisture.

The availability of Alpha model was evaluated using time series Radarsat-2 data and field soil moisture measurements. The results show good correlation between the $\left|\alpha_{\mathrm{pp}}^{T_{2}} / \alpha_{\mathrm{pp}}^{T_{1}}\right|^{2}$ and $\sigma_{\mathrm{pp}}^{T_{2}} / \sigma_{\mathrm{pp}}^{T_{1}}$, which further demonstrate the effectiveness of Alpha model for time series soil moisture retrieval.

Based on the aforementioned evaluation of rationality and availability for the Alpha model, time series Radarsat-2 data and multisensor SAR data were employed to estimate the soil moisture content over JiuLong and WanNian experimental areas, respectively.

4.2. Soil Moisture Retrieval Using Alpha Model. Time series Radarsat-2 data were applied for soil moisture retrieval over JiuLong and WanNian experimental areas. Firstly, the observation equations were constructed to eliminate the influence of surface roughness. Then, in combination with the valid range of soil moisture content, the soil moisture can be derived by the minimization of cost function. The estimated soil moisture was evaluated based on the field measurements. Figure 7 shows the comparison between the measured and estimated soil moisture using the Alpha model with multitemporal Radarsat-2 data as inputs over JiuLong and WanNian experimental areas.

The quantitative evaluation for the Alpha model was implemented on the basis of time series field measurements. The root mean square error (RMSE) and correlation coefficient (R) were selected as statistical indicators. Table 4 presents the statistical results between the estimated and measured soil moisture over JiuLong and WanNian experimental areas.

The statistical results indicated that relatively accurate soil moisture was obtained over JiuLong and WanNian experimental areas, with RMSE ranging from $0.052 \mathrm{~cm}^{3} / \mathrm{cm}^{3}$ to $0.082 \mathrm{~cm}^{3} / \mathrm{cm}^{3}$ and $R$ changing from 0.51 to 0.92 . The results demonstrated the practicability of Alpha model for agricultural area soil moisture retrieval with time series SAR data as inputs. Since October 2015, the dominated crop corn has been harvested over the study area, and the average soil moisture content is relatively low due to little precipitation during this period. There is obvious precipitation over the study area on 5 Nov. 2015; thus, the measured average soil moisture is high on 6 Nov. 2015. During the whole winter, there is relatively less precipitation over the study area. The average soil moisture content is medium over the study area on 24 Dec. 2015, 17 Jan. 2016, and 5 March 2016 due to low temperature and less evaporation. In addition, partial of the farmland was irrigated before the field measurements on 24 Dec. 2015, and 5 Mar. 2016; thus, the soil moisture content of the irrigated sampling sites is high on 24 Dec. 2015, and 5 Mar. 2016. In conclusion, the estimated soil moisture preliminarily captured the change trend of the measured time series soil moisture. However, the estimated soil moisture 

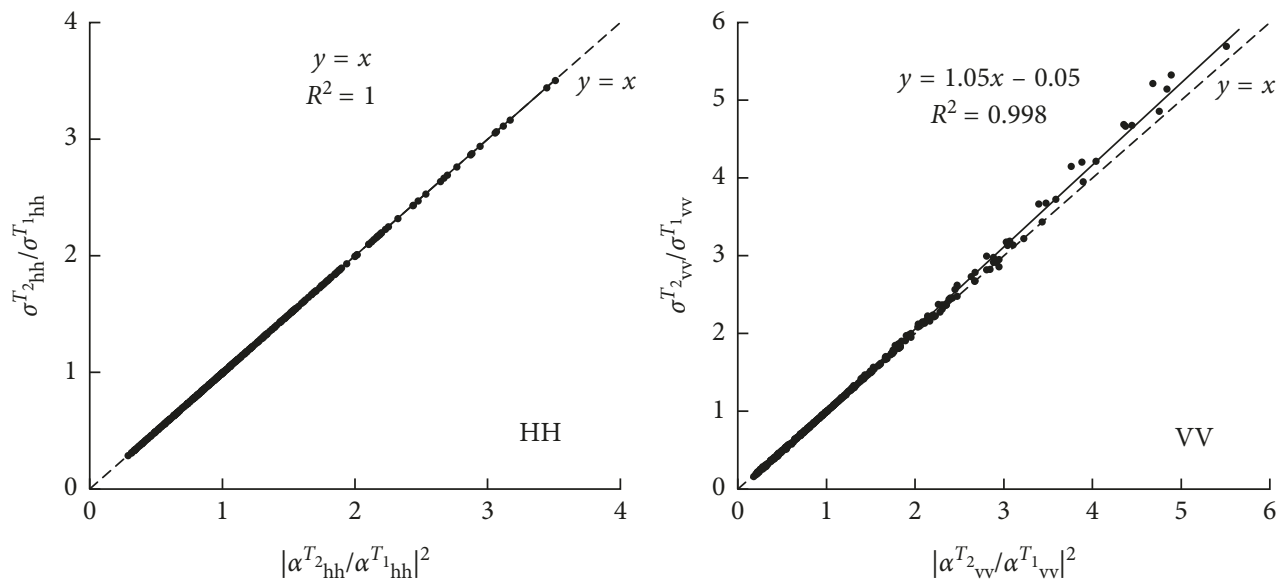

(a)
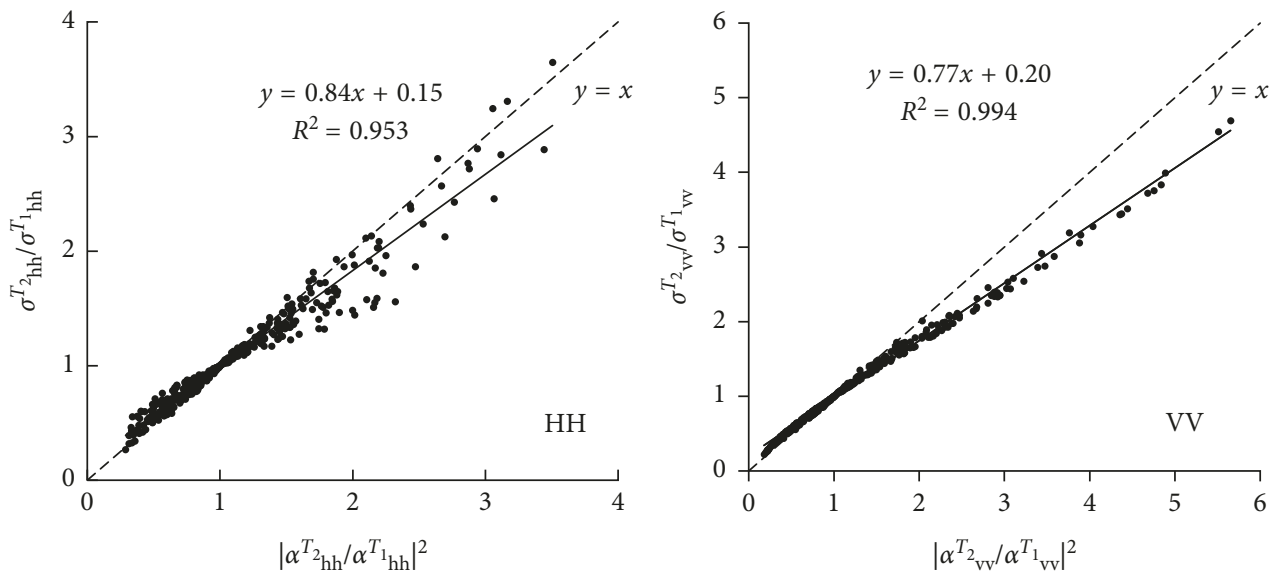

(b)

FIGURE 5: Relationships between $\left|\alpha_{\mathrm{pp}}^{T_{2}} / \alpha_{\mathrm{pp}}^{T_{1}}\right|^{2}$ and $\sigma_{\mathrm{pp}}^{T_{2}} / \sigma_{\mathrm{pp}}^{T_{1}}$ simulated by IEM and Oh models. (a) Comparison between $\sigma_{\mathrm{pp}}^{T_{2}} / \sigma_{\mathrm{pp}}^{T_{1}}$ simulated by IEM and the squared ratio of Alpha coefficient $\left|\alpha_{\mathrm{pp}}^{T_{2}} / \alpha_{\mathrm{pp}}^{T_{1}}\right|^{2}$. (b) Comparison between $\sigma_{\mathrm{pp}}^{T_{2}} / \sigma_{\mathrm{pp}}^{T_{1}}$ simulated by the Oh model and the squared ratio of Alpha coefficient $\left|\alpha_{\mathrm{pp}}^{T_{2}} / \alpha_{\mathrm{pp}}^{T_{1}}\right|^{2}$.

showed relatively large error over JiuLong and WanNian experimental areas on 6 Nov. 2015. The reason may be that the sensitivity of backscattering coefficients to soil moisture decreased when the soil moisture content is high.

4.3. Soil Moisture Retrieval Using the Developed Alpha Model. The influence of surface roughness can be effectively removed by means of the Alpha model. Observation equations can be constructed using time series SAR data; thus, soil moisture can be estimated in combination with the boundary constraint of soil moisture. Against the underdetermined system, the Alpha model fusing multisensor SAR data was developed. The independent observation equations can be constructed based on time series Radarsat-2 and Sentinel-1A data, respectively. The number of unknown parameters does not alter, while the number of effective observation equations is increased. Therefore, the underdetermined system can be transformed into an overdetermined system for soil moisture retrieval using the developed Alpha model.
During the two days interval of Radarsat-2 and Sentinel-1A acquisitions, there was no precipitation, significant temperature change, and agricultural activity, thus soil moisture content and surface roughness can be considered as constant. Therefore, time series Radarsat- 2 and Sentinel-1A data can be combined to estimate the soil moisture content by means of Alpha model. The validity of the developed Alpha model was quantitatively assessed based on continuous field measurements.

Time series Radarsat-2 data with $\mathrm{HH}$ polarization and Sentinel-1A data with VV polarization were employed to construct the observation (6) and (7), respectively. In combination with the valid soil moisture range, soil moisture content can be derived based on the comprehensive cost function (8). Figure 8 shows the comparison between the measured and estimated soil moisture using the developed Alpha model with multitemporal Radarsat-2 and Sentinel-1A data as inputs.

The developed Alpha model was quantitatively evaluated based on the measured soil moisture. Table 5 shows the quantitative statistics of the estimated soil moisture using the developed Alpha model. 

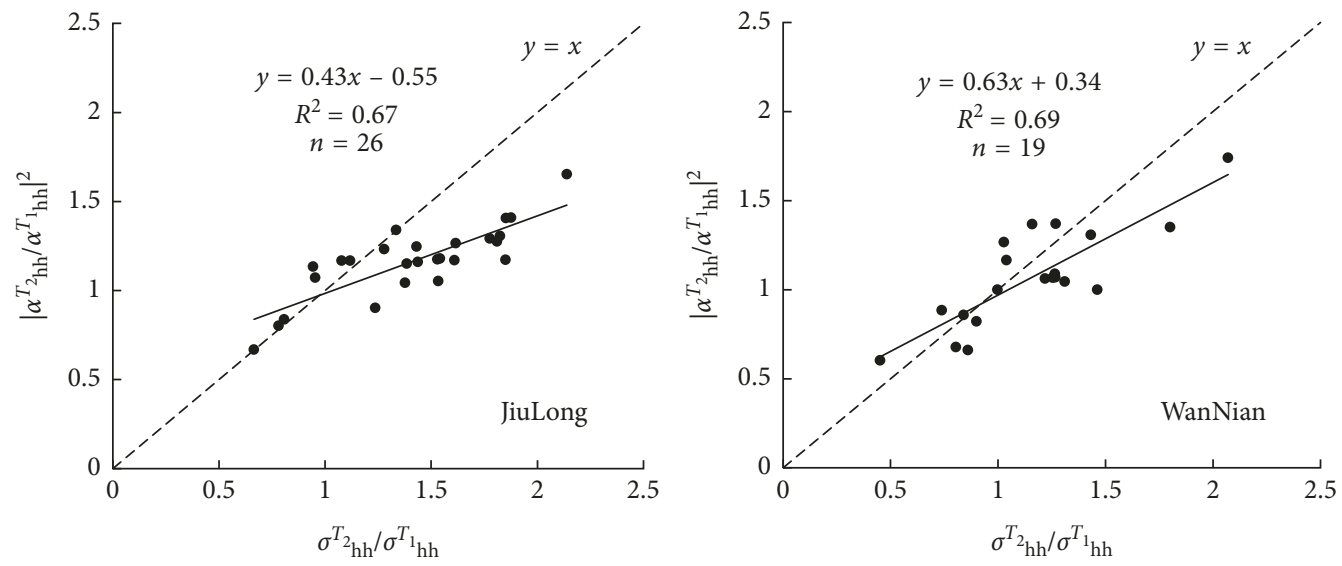

(a)
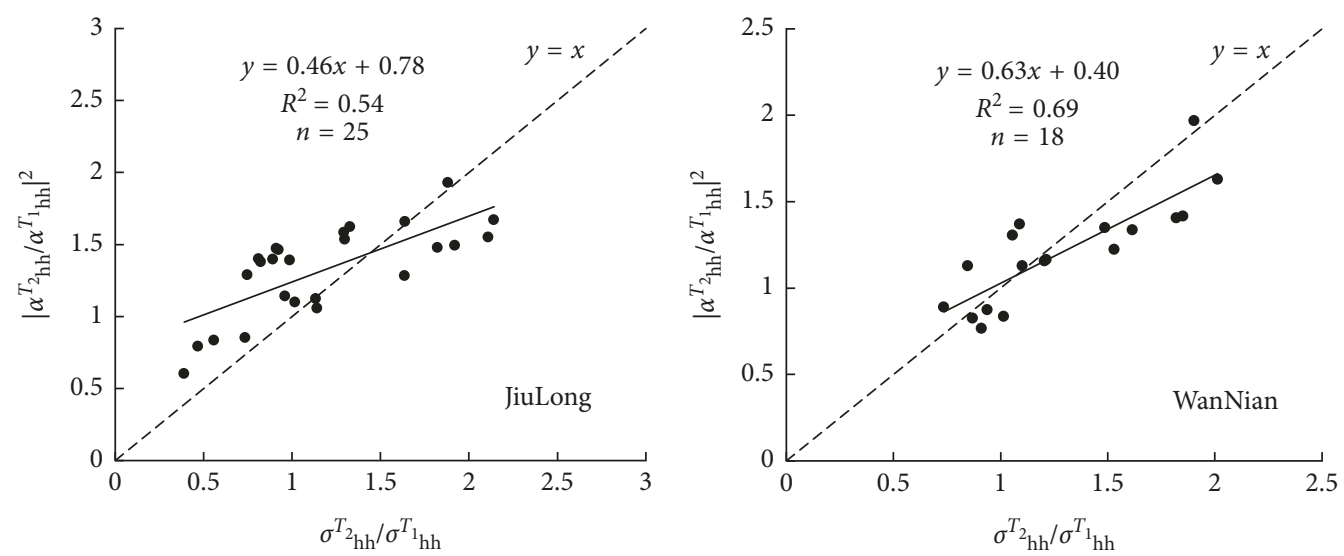

(b)
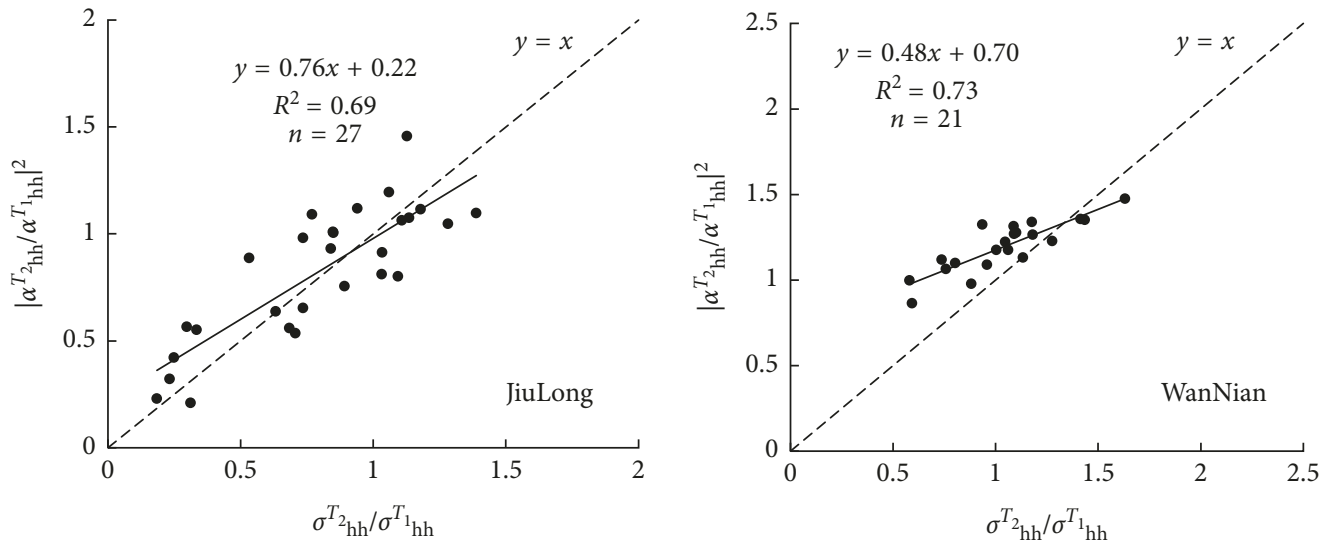

(c)

Figure 6: Evaluation for Alpha model using time series Radarsat-2 data and measured soil moisture. (a) Dataset with 24 Dec. 2015 and 17 Jan. 2016. (b) Dataset with 24 Dec. 2015 and 5 Mar. 2016. (c) Dataset with 17 Jan. 2016 and 5 Mar. 2016.

The results indicated that accurate time series soil moisture was obtained over JiuLong and WanNian experimental areas with RMSE ranging from $0.048 \mathrm{~cm}^{3} / \mathrm{cm}^{3}$ to $0.068 \mathrm{~cm}^{3} / \mathrm{cm}^{3}$ and $R$ changing from 0.54 to 0.91 . The estimated soil moisture shows good agreement with the field measurements. The quantitative results demonstrated the practicability of the developed Alpha model for soil moisture retrieval over bare agricultural areas.

In addition, the comparison between the Alpha approximation model and the developed Alpha model was implemented based on the measured soil moisture. Figure 9 shows the comparison of soil moisture retrieval between the Alpha model and the developed method.

The quantitative comparison between the Alpha model and the developed method indicated that time series soil moisture retrieval performance can be improved when multisensor SAR data was combined to estimate soil moisture. In addition, the comparison of the average accuracy between the Alpha approximation model and the 

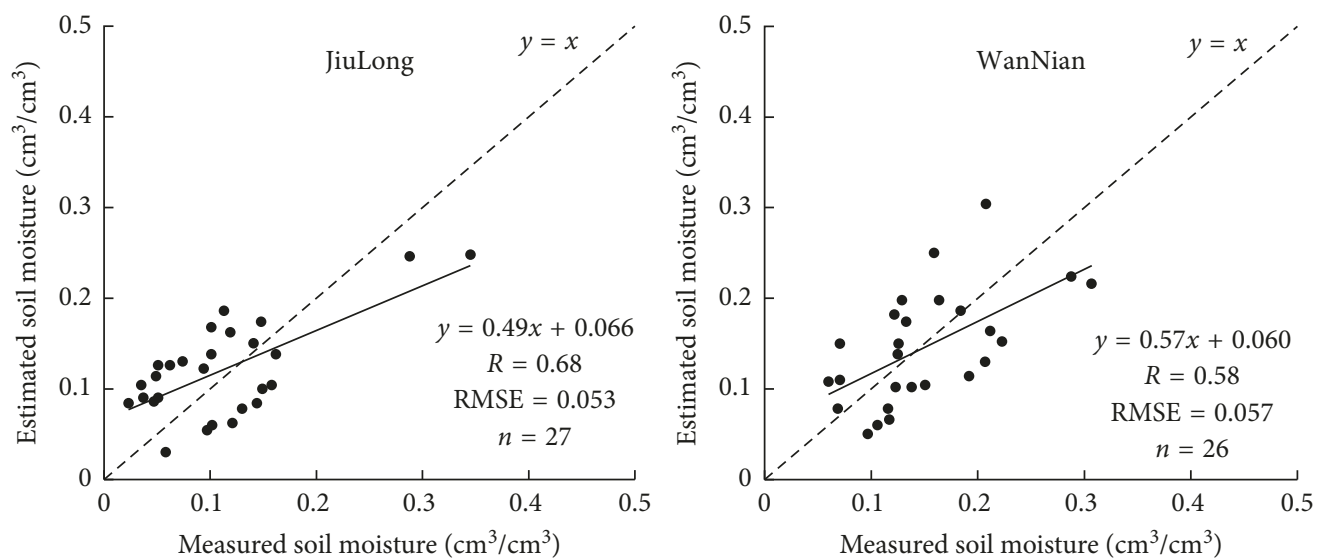

(a)
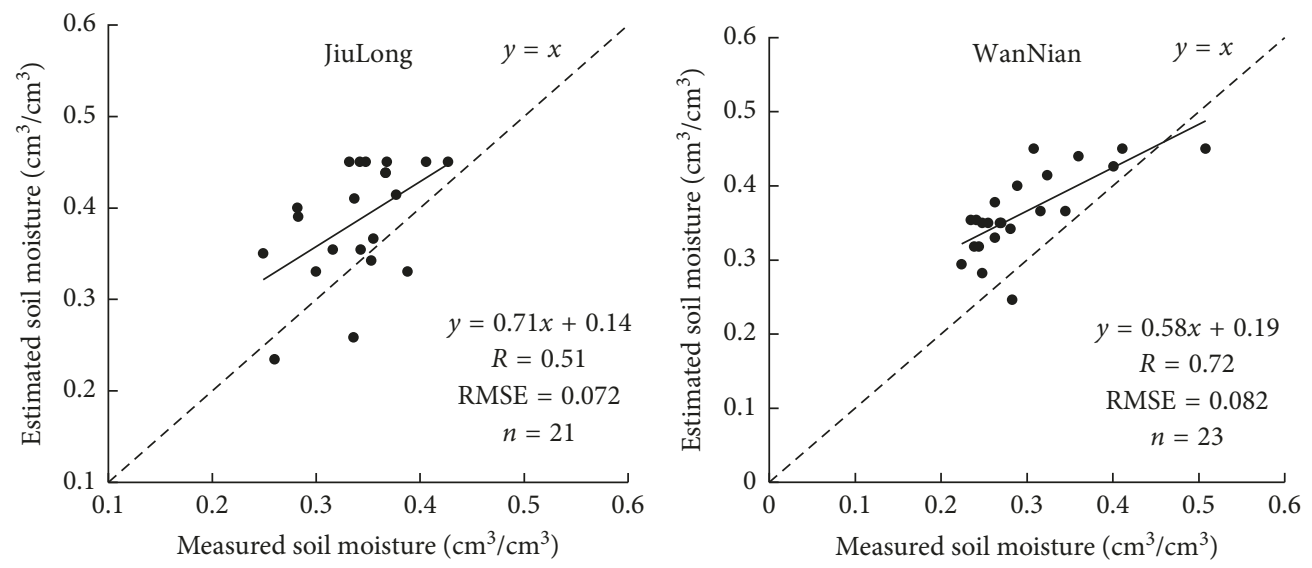

(b)
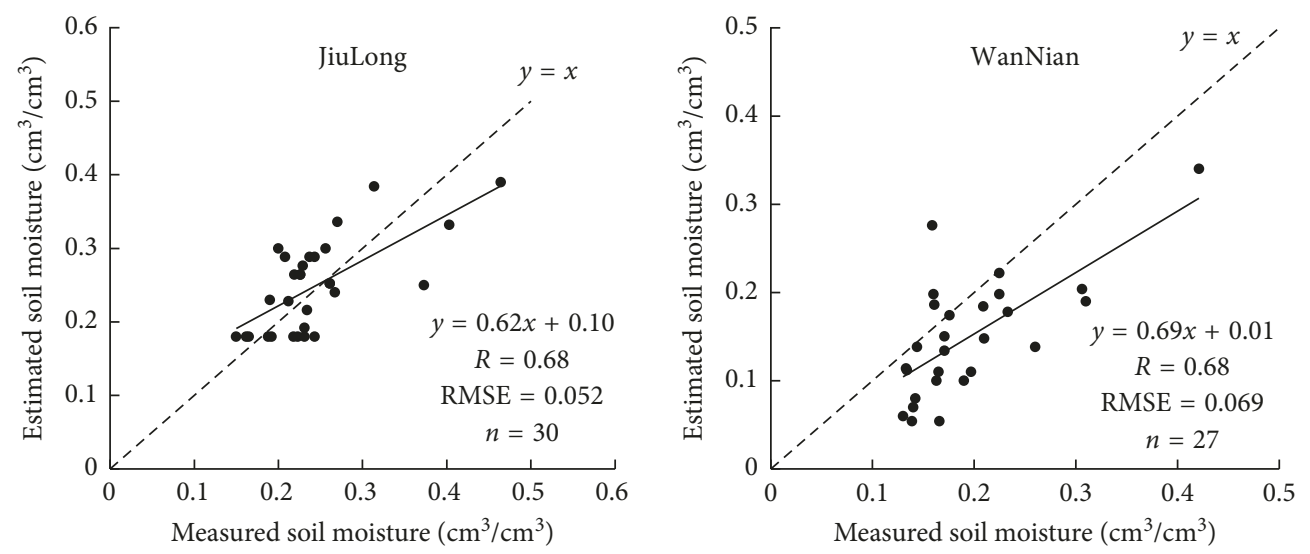

(c)

FIgURE 7: Continued. 

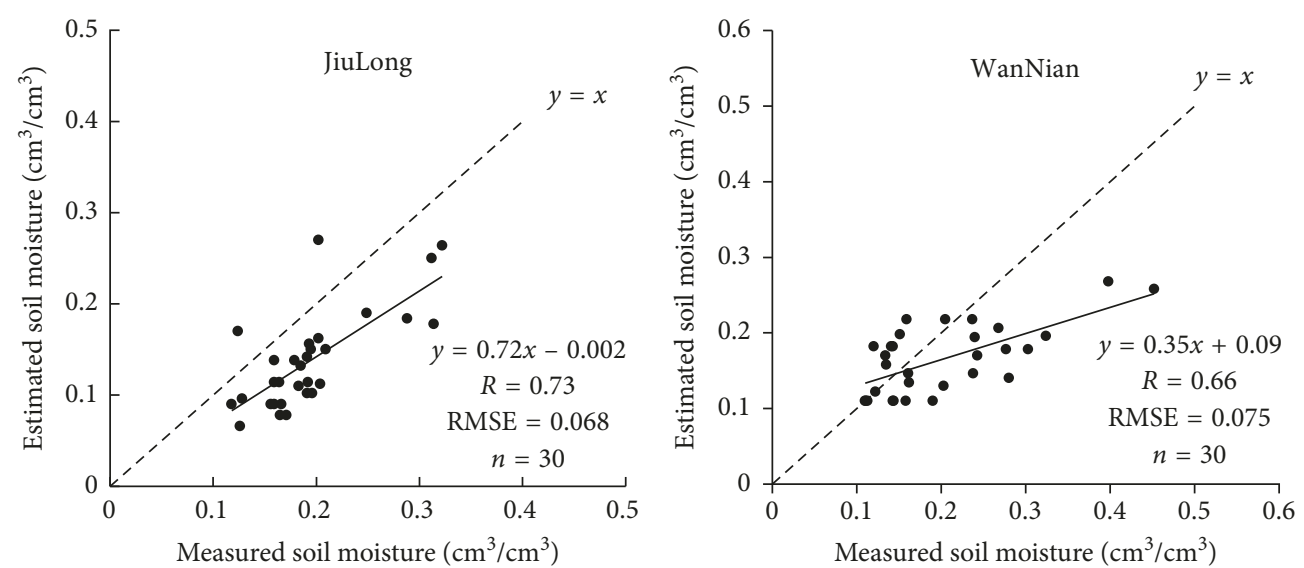

(d)
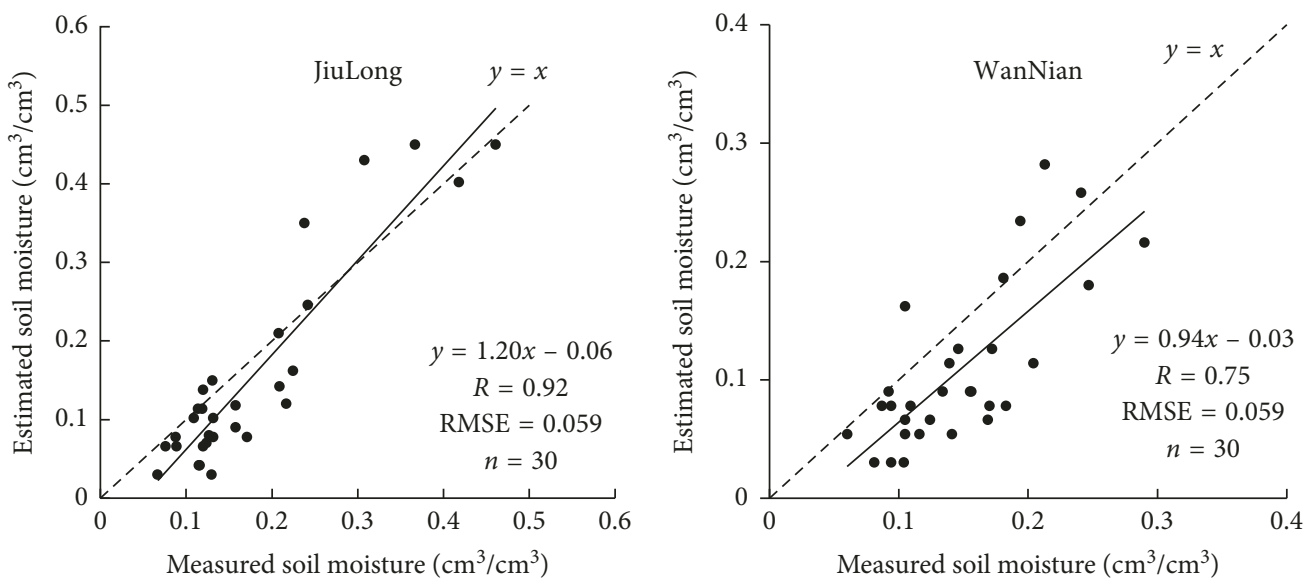

(e)

Figure 7: Comparison between the measured and estimated soil moisture using the Alpha model. (a) Comparison between the estimated and measured soil moisture on 13 Oct. 2015. (b) Comparison between the estimated and measured soil moisture on 6 Nov. 2015. (c) Comparison between the estimated and measured soil moisture on 24 Dec. 2015. (d) Comparison between the estimated and measured soil moisture on 17 Jan. 2016. (e) Comparison between the estimated and measured soil moisture on 5 Mar. 2016.

developed method was implemented. The average RMSE of the developed method with $0.051 \mathrm{~cm}^{3} / \mathrm{cm}^{3}$ is less than the original Alpha approximation model with $0.065 \mathrm{~cm}^{3} / \mathrm{cm}^{3}$. The effectiveness of the Alpha model fusing multisensor SAR data for soil moisture retrieval was further verified.

4.4. Discussion. In order to evaluate the spatial characteristics of the estimated soil moisture using the developed Alpha model, the soil moisture content at regional scale was estimated over the study area. Soil moisture maps from 13 Oct. 2015 to 5 Mar. 2016 were obtained, respectively, shown as Figures 10(a)-10(e). The qualitative results can also capture the soil moisture changes from 13 Oct. 2015 to 5 Mar. 2016. Therefore, the developed Alpha model can be used for soil moisture retrieval over agricultural areas.

For the developed Alpha model, time series multisensor SAR data are required for soil moisture retrieval. However, with the development of SAR technique, the concurrent acquisition of SAR data with different frequency, polarization, and incidence angle can be achieved and hence provide the basis of soil moisture retrieval by means of multisensor SAR
TABLE 4: Quantitative evaluation of the estimated soil moisture using Alpha model.

\begin{tabular}{lccc}
\hline Date & Statistical indicators & JiuLong & WanNian \\
\hline \multirow{3}{*}{ 13 Oct. 2015 } & RMSE $\left(\mathrm{cm}^{3} / \mathrm{cm}^{3}\right)$ & 0.053 & 0.057 \\
& $R$ & 0.68 & 0.58 \\
& Sampling number & 27 & 26 \\
\hline \multirow{3}{*}{ N Nov. 2015 } & RMSE $\left(\mathrm{cm}^{3} / \mathrm{cm}^{3}\right)$ & 0.072 & 0.082 \\
& $R$ & 0.51 & 0.72 \\
& Sampling number & 21 & 23 \\
\hline \multirow{3}{*}{ 24 Dec. 2015 } & RMSE $\left(\mathrm{cm}^{3} / \mathrm{cm}^{3}\right)$ & 0.052 & 0.069 \\
& $R$ & 0.68 & 0.68 \\
& Sampling number & 30 & 27 \\
\hline \multirow{4}{*}{ 17 Jan. 2016 } & RMSE $\left(\mathrm{cm}^{3} / \mathrm{cm}^{3}\right)$ & 0.068 & 0.075 \\
& $R$ & 0.73 & 0.66 \\
& Sampling number & 30 & 30 \\
\hline \multirow{3}{*}{ 5 Mar. 2016 } & RMSE $\left(\mathrm{cm}^{3} / \mathrm{cm}^{3}\right)$ & 0.059 & 0.059 \\
& $R$ & 0.92 & 0.75 \\
& Sampling number & 30 & 30 \\
\hline
\end{tabular}

data with different system configuration parameters. The rationale is that the SAR signal is sensitive to soil surface properties in a different way and to a different extent 

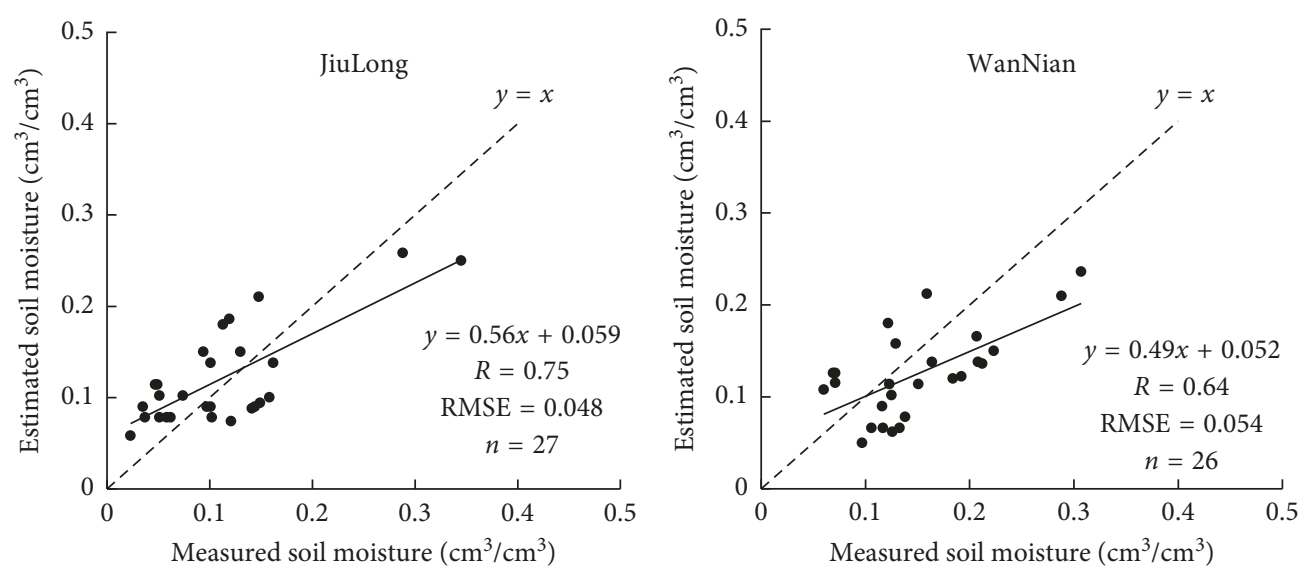

(a)
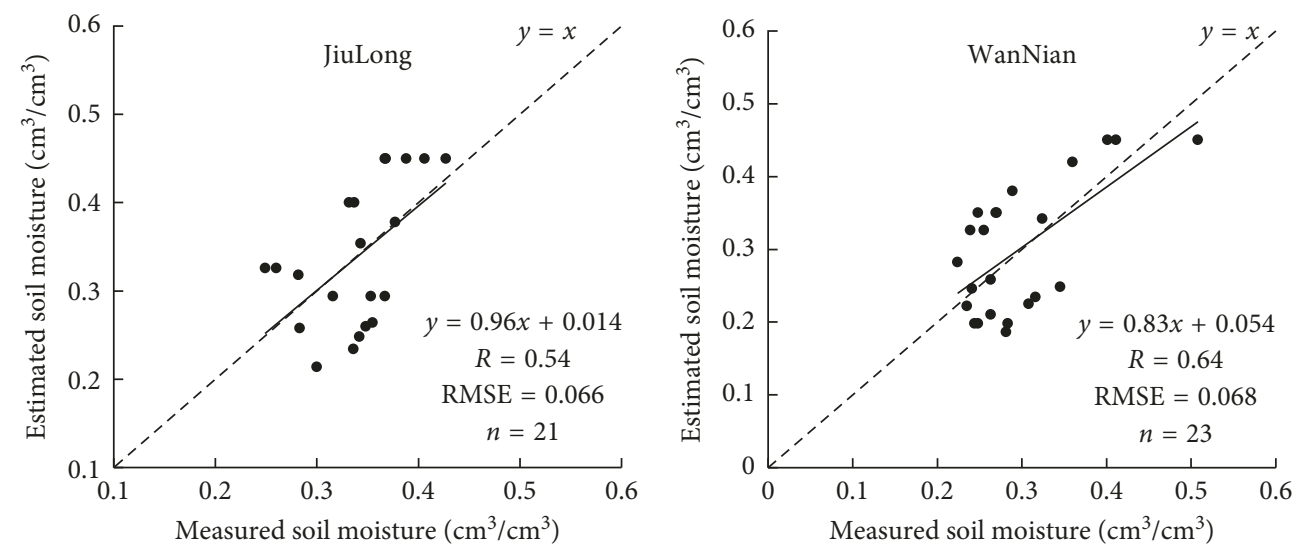

(b)
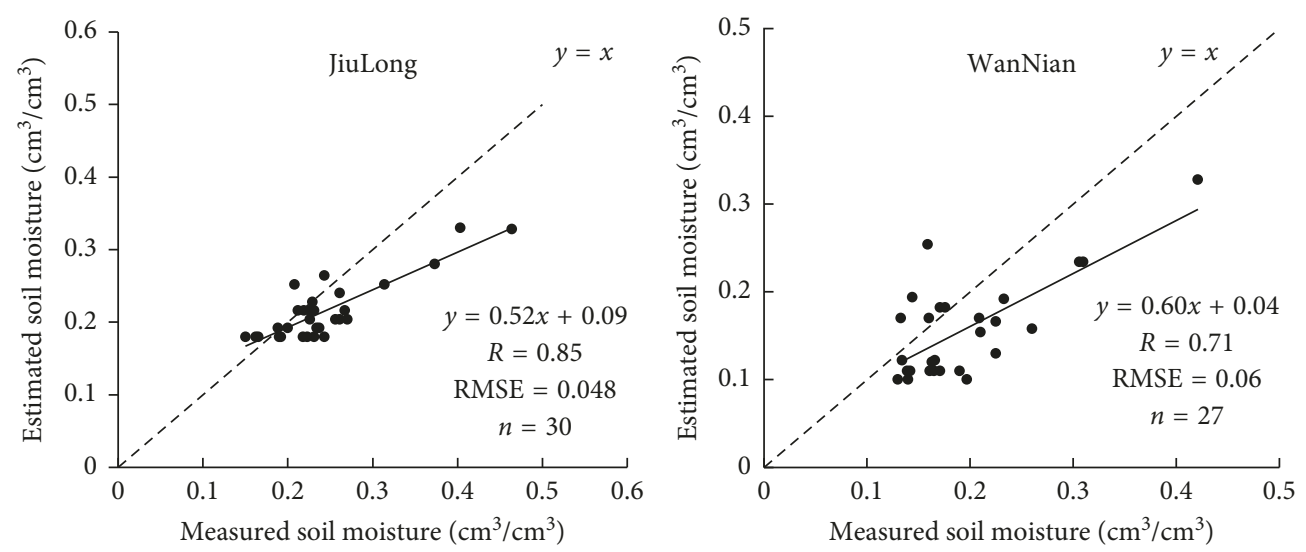

(c)

Figure 8: Continued. 

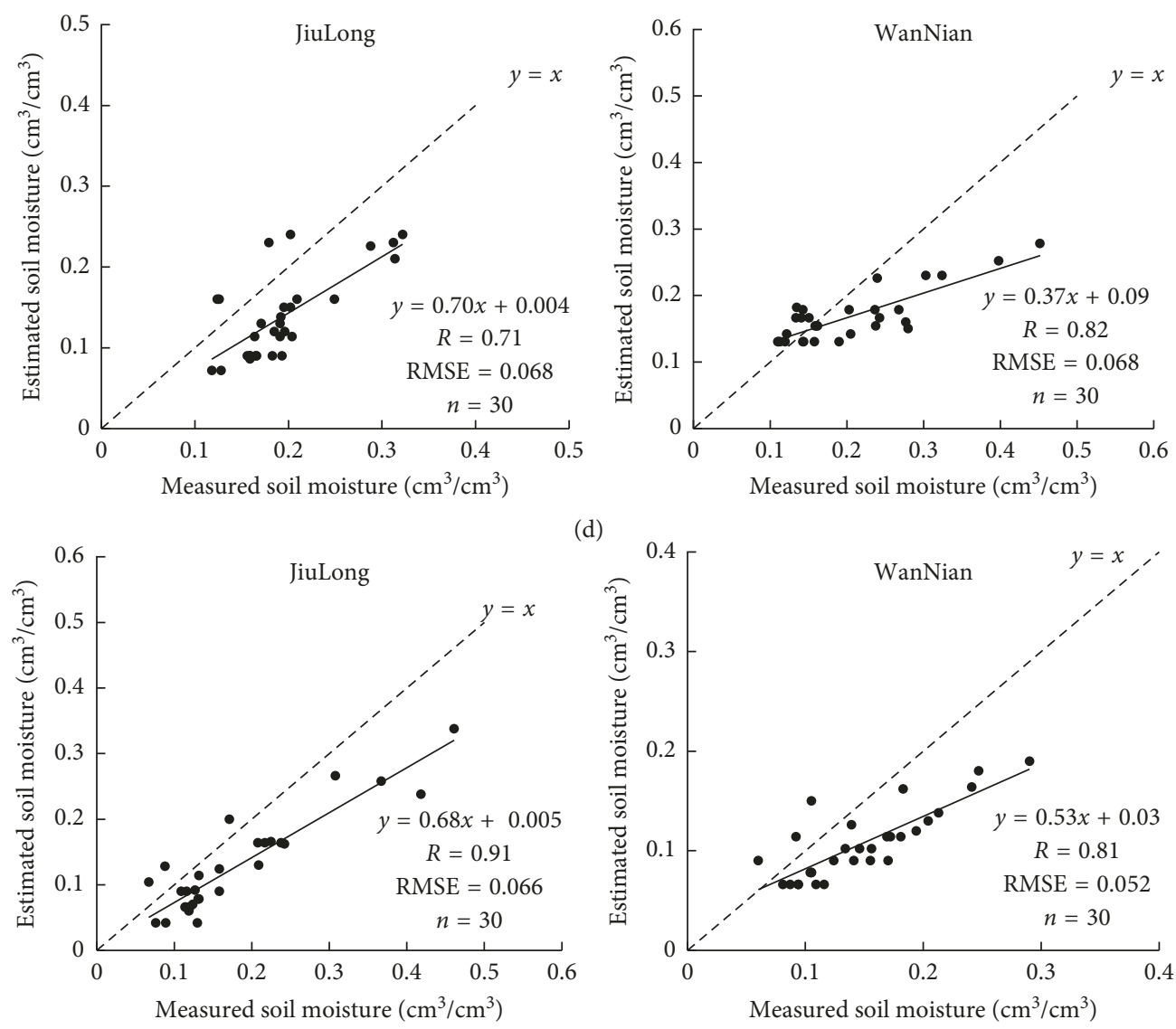

d)

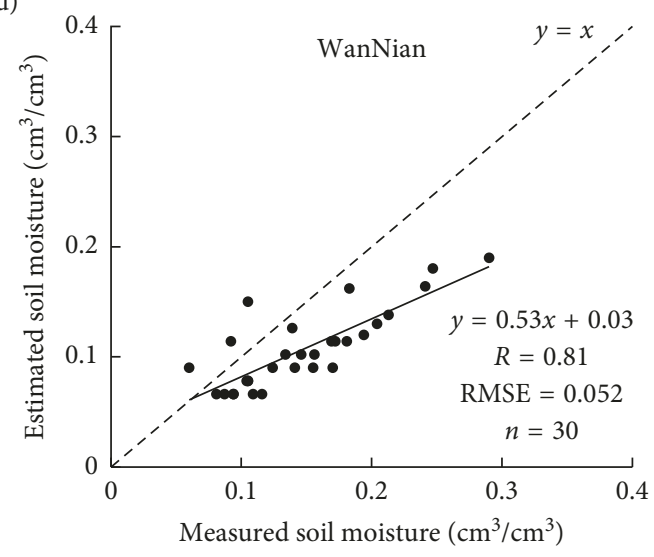

(e)

Figure 8: Comparison between the measured and estimated soil moisture using the developed Alpha model. (a) Comparison between the estimated and measured soil moisture on 13 Oct. 2015. (b) Comparison between the estimated and measured soil moisture on 6 Nov. 2015. (c) Comparison between the estimated and measured soil moisture on 24 Dec. 2015. (d) Comparison between the estimated and measured soil moisture on 17 Jan. 2016. (e) Comparison between the estimated and measured soil moisture on 5 Mar. 2016.

TABLE 5: Quantitative evaluation of estimated soil moisture using the developed Alpha model.

\begin{tabular}{lccc}
\hline Date & Statistical indicators & JiuLong & WanNian \\
\hline \multirow{4}{*}{ 13 Oct. 2015 } & RMSE $\left(\mathrm{cm}^{3} / \mathrm{cm}^{3}\right)$ & 0.048 & 0.054 \\
& $R$ & 0.75 & 0.64 \\
& Sampling number & 27 & 26 \\
\hline \multirow{3}{*}{ 6 Nov. 2015 } & RMSE $\left(\mathrm{cm}^{3} / \mathrm{cm}^{3}\right)$ & 0.066 & 0.068 \\
& $R$ & 0.54 & 0.64 \\
& Sampling number & 21 & 23 \\
\hline \multirow{3}{*}{ 24 Dec. 2015} & RMSE $\left(\mathrm{cm}^{3} / \mathrm{cm}^{3}\right)$ & 0.048 & 0.06 \\
& $R$ & 0.85 & 0.71 \\
& Sampling number & 30 & 27 \\
\hline \multirow{3}{*}{ 17 Jan. 2016 } & RMSE $\left(\mathrm{cm}^{3} / \mathrm{cm}^{3}\right)$ & 0.068 & 0.068 \\
& $R$ & 0.71 & 0.82 \\
& Sampling number & 30 & 30 \\
\hline \multirow{3}{*}{ 5 Mar. 2016 } & RMSE $\left(\mathrm{cm}^{3} / \mathrm{cm}^{3}\right)$ & 0.066 & 0.052 \\
& $R$ & 0.91 & 0.81 \\
& Sampling number & 30 & 30 \\
\hline
\end{tabular}

depending on the SAR frequency, polarization, and incidence angle. Accordingly, the confounding effect of soil moisture and surface roughness may be decoupled by means of the multiangle, multipolarization, and multifrequency SAR data.
The combination of SAR information acquired with different system configurations leads to a better characterization of the parameters affecting the SAR signal and thus to an accurate estimation of soil moisture content [42]. Therefore, the developed Alpha model is promising for time series soil moisture retrieval over agricultural areas. In addition, the $\mathrm{HH}$ and VV polarization backscatter information for single SAR sensor may have certain correlation; thus, the combination of $\mathrm{HH}$ and VV backscatter may not improve soil moisture estimation obviously [32]. Consequently, the combination of time series Radarsat-2 and Sentinel-1A data with different incidence angle and polarization improved the soil moisture estimation.

It should be noticed that the uncertainties of soil moisture retrieval originated from different aspects. Firstly, the uncertainties aroused from SAR data were unpredicted, especially for different SAR satellites. Speckle noise of the SAR image, radiometric calibration and registration errors from SAR data, and inevitable field measurements errors would induce the deviation of soil moisture retrieval. Secondly, the uncertainties resulted from the inversion model was inevitable. The Alpha approximation model may not be robust enough for specific experimental areas. Thirdly, 


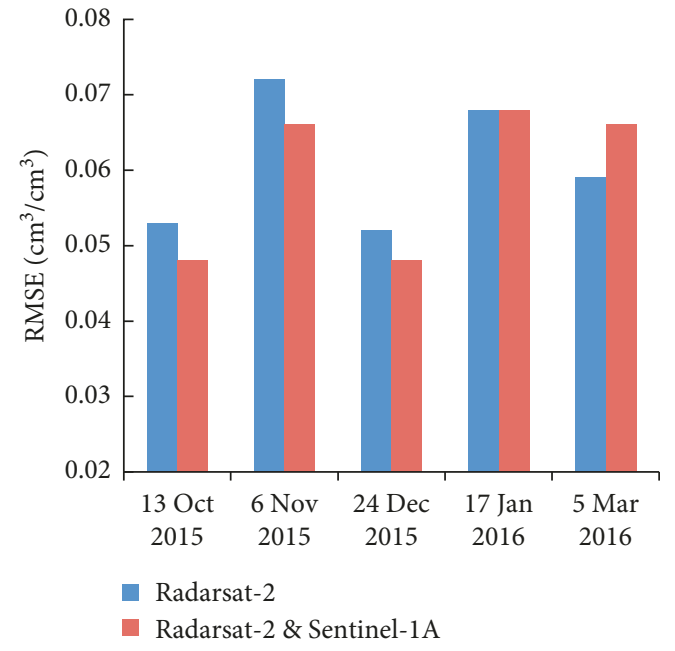

(a)

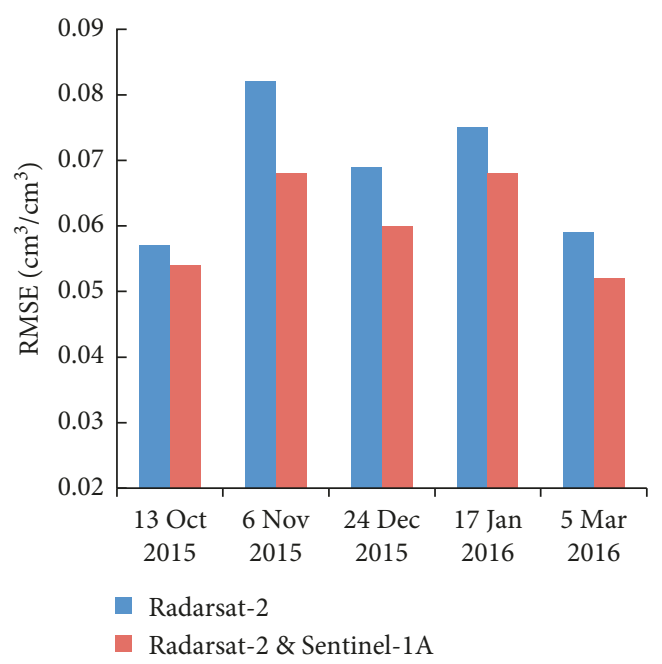

(b)

Figure 9: Comparison of soil moisture retrieval between the Alpha model and the developed method. (a) JiuLong experimental dataset. (b) WanNian experimental dataset.

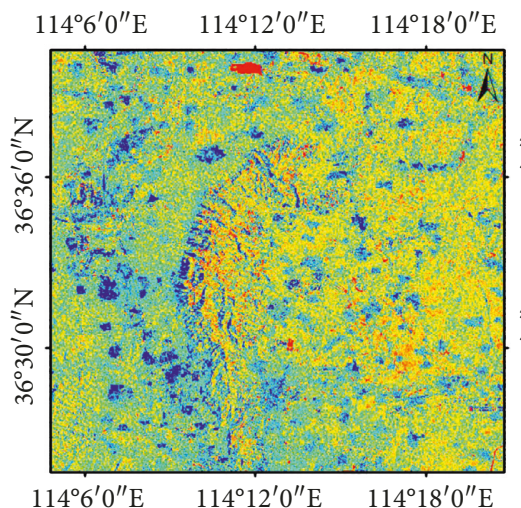

(a)

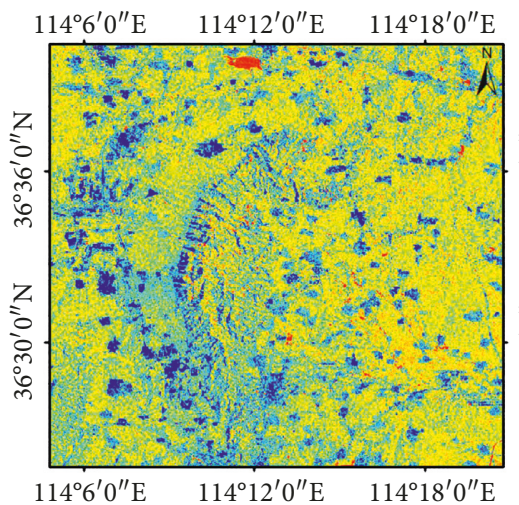

(d)

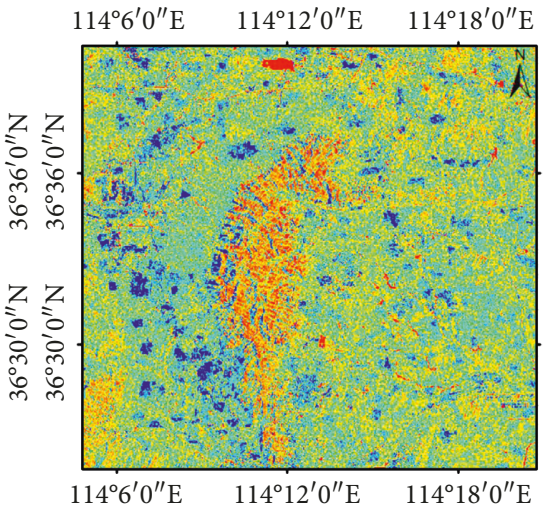

(b)

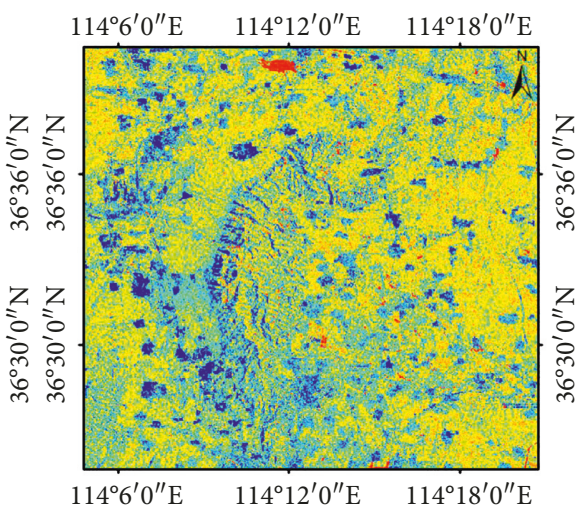

(e)

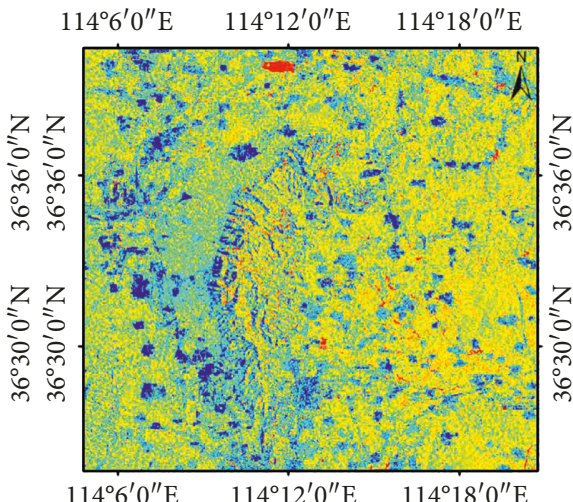

(c)

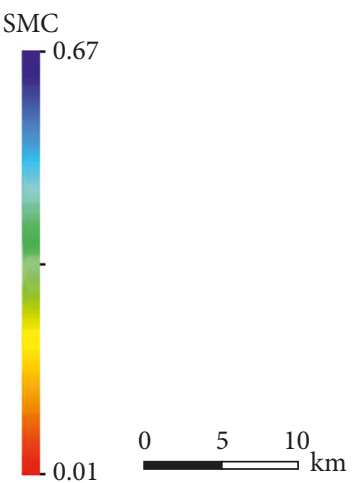

Figure 10: Soil moisture maps of the study area using the developed Alpha model. (a)-(e) represent the soil moisture maps obtained on 13 Oct. 2015, 6 Nov. 2015, 24 Dec. 2015, 17 Jan. 2016, and 5 Mar. 2016, respectively.

the assumptions were that soil surface roughness is constant during the period of SAR data acquisitions, and soil moisture does not change during two days interval of Radarsat-2 and Sentinel-1A acquisitions. All of the above aspects may induce the uncertainties for soil moisture retrieval. An accurate uncertainty assessment for soil moisture estimation contributed to evaluate the applicability and validity of the developed method. 


\section{Conclusions}

Based on time series SAR data, the Alpha approximation model was quantitatively assessed for soil moisture retrieval. This approach has certain theoretical foundation structuring the relationship between the ratio of backscattering coefficients and squared ratio of Alpha coefficients and does not require the prior knowledge of surface roughness. Therefore, this research focused on the Alpha model for soil moisture retrieval. Considering the deficiency of this method, the Alpha model fusing multisensor SAR data was developed to solve the underdetermined system. The evaluation for the Alpha model and the developed method was implemented based on the multitemporal Radarsat-2 and Sentinel-1A data, as well as continuous field measurements. The following conclusions can be derived:

(1) The Alpha model can capture the change trend of time series soil moisture content. However, the underdetermined system may deteriorate the accuracy and reliability of estimated soil moisture.

(2) Against the deficiency of Alpha model, the Alpha model fusing time series Radarsat- 2 and Sentinel-1A data was developed to transform the underdetermined system into overdetermined system. The effectiveness of the developed Alpha model was demonstrated based on time series Radarsat-2, Sentinel-1A data, and field measurements over bare agricultural areas.

It should be remarked that the experimental area is relatively small, and the available dataset is not very sufficient for drawing global considerations. However, the developed approach is promising for obtaining an improved accuracy for soil moisture retrieval with respect to singlesensor SAR data. The main limitation for generalizing this approach is the simultaneous acquisitions of multisensor SAR data. However, with the development of SAR techniques and increasing research on SAR satellites, novel SAR systems may provide abundant data sources for soil moisture retrieval. Therefore, the research on multisensor and multitemporal SAR data for soil moisture retrieval is promising.

\section{Data Availability}

The data used in our research include time series Radarsat-2, Sentinel-1A data, and field-measured soil surface parameters. The Sentinel-1A data are available on the ESA website (https://scihub.copernicus.eu/dhus/\#/home). The Radarsat-2 data were acquired from the commercial channels on http:// www.ev-image.com/. The soil surface parameters were measured during the SAR data acquisitions. Extensive expenses and efforts were expended on the data acquisitions. Furthermore, the data used in our research are not only used for academic research but also for project application (Special Fund for Public Projects of National Administration of Surveying, Mapping, and Geoinformation of China). Therefore, at present, sections of the data are not available. Statistical aspects of the data used to support the findings of this study are included within the article.

\section{Conflicts of Interest}

The authors declare that they have no conflicts of interest.

\section{Acknowledgments}

The authors wish to thank the ESA for providing the NEST, SNAP software, and Sentinel-1A data. The authors would like to thank Jilei Huang, Junkai Yang, Hua Chen, Lei Wang, $\mathrm{Da} \mathrm{Li}$, Meinan Zheng, and Sen Du for their help with extensive field measurements. This research was supported by the National Key R\&D Programme of China (no. 2017YFB0502700), Civilian Space Programme of China (no. D010102), National Basic Surveying and Mapping Science and Technology Plan (no. 2018KJ0204/2018KJ0304), and the Special Fund for Public Projects of National Administration of Surveying, Mapping, and Geoinformation of China (no. 201412016).

\section{References}

[1] F. T. Ulaby, P. C. Dubois, and J. van Zyl, "Radar mapping of surface soil moisture," Journal of Hydrology, vol. 184, no. 1-2, pp. 57-84, 1996.

[2] P. C. Dubois, J. van Zyl, and T. Engman, "Measuring soil moisture with imaging radars," IEEE Transactions on Geoscience and Remote Sensing, vol. 33, no. 4, pp. 915-926, 1995.

[3] D. Entekhabi, E. G. Njoku, P. E. O’Neill et al., “The Soil Moisture Active Passive (SMAP) mission," in Proceedings of the IEEE International Geoscience and Remote Sensing Symposium, pp. 704-716, Honolulu, HA, USA, July 2010.

[4] M. C. Dobson and F. T. Ulaby, "Active microwave soil moisture research," IEEE Transactions on Geoscience and Remote Sensing, vol. 24, no. 1, pp. 23-36, 1986.

[5] S. Paloscia, P. Pampaloni, S. Pettinato, and E. Santi, "A comparison of algorithms for retrieving soil moisture from ENVISAT/ASAR images," IEEE Transactions on Geoscience and Remote Sensing, vol. 46, no. 10, pp. 3274-3284, 2008.

[6] S. Paloscia, S. Pettinato, and E. Santi, "Soil moisture mapping using Sentinel-1 images: algorithm and preliminary validation," Remote Sensing of Environment, vol. 134, pp. 234-248, 2013.

[7] J. Y. Zeng, Z. Li, Q. Chen, H. Y. Bi, J. X. Qiu, and P. F. Zou, "Evaluation of remotely sensed and reanalysis soil moisture products over the Tibetan Plateau using in-situ observations," Remote Sensing of Environment, vol. 163, pp. 91-110, 2015.

[8] J. Y. Zeng, Z. Li, Q. Chen, and H. Y. Bi, "Method for soil moisture and surface temperature estimation in the Tibetan Plateau using spaceborne radiometer observations," IEEE Geoscience and Remote Sensing Letters, vol. 12, no. 1, pp. 97-101, 2015.

[9] Q. Y. Meng, Q. X. Xie, C. M. Wang, J. X. Ma, Y. X. Sun, and L. L. Zhang, "A fusion approach of the improved Dubois model and best canopy water retrieval models to retrieve soil moisture through all maize growth stages from Radarsat-2 and Landsat-8 data," Environmental Earth Sciences, vol. 75, no. 20, p. 1377, 2016.

[10] S. G. Lei, H. Q. Chen, Z. F. Bian, and Z. G. Liu, "Evaluation of integrating topographic wetness index with backscattering coefficient of TerraSAR-X image for soil moisture estimation in a mountainous region," Ecological Indicators, vol. 61, pp. 624-633, 2016. 
[11] S. B. Kim, L. Tsang, and J. T. Johnson, "Soil moisture retrieval using time-series radar observations over bare surfaces," IEEE Transactions on Geoscience and Remote Sensing, vol. 50, no. 5, pp. 1853-1863, 2012.

[12] N. Pierdicca, L. Pulvirenti, and G. Pace, "A prototype software package to retrieve soil moisture from Sentinel-1 data by using a bayesian multitemporal algorithm," IEEE Journal of Selected Topics in Applied Earth Observations and Remote Sensing, vol. 7, no. 1, pp. 153-166, 2014.

[13] H. S. Srivastava, P. Patel, M. L. Manchanda, and S. Adiga, "Use of multi-incidence angle RADARSAT-1 SAR data to incorporate the effect of surface roughness in soil moisture estimation," IEEE Transactions on Geoscience and Remote Sensing, vol. 41, no. 7, pp. 1638-1640, 2003.

[14] H. S. Srivastava, P. Patel, Y. Sharma, and R. R. Navalgund, "Large-area soil moisture estimation using multi-incidence angle RADARSAT-1 SAR data," IEEE Transactions on Geoscience and Remote Sensing, vol. 47, no. 8, pp. 2528-2535, 2009.

[15] M. Zribi, N. Baghdadi, N. Holah, and O. Fafin, "New methodology for soil surface moisture estimation and its application to ENVISAT-ASAR multi-incidence data inversion," Remote Sensing of Environment, vol. 96, no. 3-4, pp. 485-496, 2005.

[16] Y. Oh, K. Sarabandi, and F. T. Ulaby, "An empirical model and inversion technique for radar scattering from bare soil surfaces," IEEE Transactions on Geoscience and Remote Sensing, vol. 30, no. 2, pp. 370-381, 1992.

[17] J. C. Shi, J. Wang, A. Y. Hsu, P. E. O’Neill, and E. T. Engman, "Estimation of bare surface soil moisture and surface roughness parameter using L-band SAR image data," IEEE Transactions on Geoscience and Remote Sensing, vol. 35, no. 5, pp. 1254-1266, 1997.

[18] A. Merzouki and H. McNairn, "A hybrid (multi-angle and multipolarization) approach to soil moisture retrieval using the integral equation model: preparing for the RADARSAT constellation mission," Canadian Journal of Remote Sensing, vol. 41, no. 5, pp. 349-362, 2015.

[19] Q. X. Xie, Q. Y. Meng, L. L. Zhang, C. M. Wang, Y. X. Sun, and Z. H. Sun, "A soil moisture retrieval method based on typical polarization decomposition techniques for a maize field from full-polarization Radarsat-2 data," Remote Sensing, vol. 9, no. 2, p. 168, 2017.

[20] R. Bindlish and A. P. Barros, "Multifrequency soil moisture inversion from SAR measurements with the use of IEM," Remote Sensing of Environment, vol. 71, no. 1, pp. 67-88, 2000.

[21] N. Baghdadi, S. Gaultier, and C. King, "Retrieving surface roughness and soil moisture from synthetic aperture radar (SAR) data using neural networks," Canadian Journal of Remote Sensing, vol. 28, no. 5, pp. 701-711, 2002.

[22] N. Pierdicca, L. Pulvirenti, and C. Bignami, "Soil moisture estimation over vegetated terrains using multitemporal remote sensing data," Remote Sensing of Environment, vol. 114, no. 2, pp. 440-448, 2010.

[23] E. J. M. Rignot and J. van Zyl, "Change detection techniques for ERS-1 SAR data," IEEE Transactions on Geoscience and Remote Sensing, vol. 31, no. 4, pp. 896-906, 1993.

[24] W. Wagner, G. Lemoine, and H. Rott, "A method for estimating soil moisture from ERS scatterometer and soil data," Remote Sensing of Environment, vol. 70, no. 2, pp. 191-207, 1999.

[25] H. Yang, J. C. Shi, Z. Li, and H. D. Guo, “Temporal and spatial soil moisture change pattern detection in an agricultural area using multi-temporal Radarsat ScanSAR data," International Journal of Remote Sensing, vol. 27, no. 19, pp. 4199-4212, 2006.

[26] Z. Bartalis, W. Wagner, V. Naeimi et al., "Initial soil moisture retrievals from the METOP-A Advanced Scatterometer (ASCAT)," Geophysical Research Letters, vol. 34, no. 20, pp. 5-9, 2007.

[27] C. Pathe, W. Wagner, D. Sabel, M. Doubkova, and J. B. Basara, "Using ENVISAT ASAR global mode data for surface soil moisture retrieval over Oklahoma, USA," IEEE Transactions on Geoscience and Remote Sensing, vol. 47, no. 2, pp. 468-480, 2009.

[28] A. Balenzano, F. Mattia, G. Satalino, and M. W. J. Davidson, "Dense temporal series of C- and L-band SAR data for soil moisture retrieval over agricultural crops," IEEE Journal of Selected Topics in Applied Earth Observations and Remote Sensing, vol. 4, no. 2, pp. 439-450, 2011.

[29] A. Balenzano, F. Mattia, G. Satalino, V. Pauwels, and P. Snoeij, "SMOSAR algorithm for soil moisture retrieval using Sentinel-1 data," in Proceedings of IEEE International Geoscience and Remote Sensing Symposium, pp. 1200-1203, Munich, Germany, July 2012.

[30] G. Satalino, F. Mattia, A. Balenzano, R. Panciera, and J. Walker, "Soil moisture maps from time series of PALSAR-1 scansar data over Australia," in Proceedings of IEEE International Geoscience and Remote Sensing Symposium, pp. 719-722, Melbourne, VIC, Australia, 2013.

[31] J. D. Ouellette, J. T. Johnson, A. Balenzano, and F. Mattia, “A study of soil moisture estimation from multitemporal L-band radar observations of vegetated surfaces," in Proceedings of EUSAR, Berlin, Germany, 2014.

[32] J. D. Ouellette, J. T. Johnson, A. Balenzano et al., “A timeseries approach to estimating soil moisture from vegetated surfaces using L-band radar backscatter," IEEE Transactions on Geoscience and Remote Sensing, vol. 55, no. 6, pp. 31863193, 2017.

[33] A. Balenzano, G. Satalino, F. Lovergine, M. Rinaldi, and $\mathrm{V}$. Iacobellis, "On the use of temporal series of L- and X-band SAR data for soil moisture retrieval. Capitanata plain case study," European Journal of Remote Sensing, vol. 46, no. 1, pp. 721-737, 2013.

[34] F. Mattia, A. Balenzano, G. Satalino, and V. Pauwels, "A SAR soil moisture retrieval algorithm inverting the temporal changes of radar backscatter," in Proceedings of EUSAR, Berlin, Germany, 2014.

[35] S. Kweon and Y. Oh, "Estimation of soil moisture and surface roughness from single-polarized radar data for bare soil surface and comparison with dual- and quad-polarization cases," IEEE Transactions on Geoscience and Remote Sensing, vol. 52, no. 7, pp. 4056-4064, 2014.

[36] L. He, Q. M. Qin, R. Panciera, M. Tanase, J. P. Walker, and Y. Hong, "An extension of the alpha approximation method for soil moisture estimation using time-series SAR data over bare soil surfaces," IEEE Geoscience and Remote Sensing Letters, vol. 14, no. 8, pp. 1328-1332, 2017.

[37] J. S. Lee, "Digital image enhancement and noise filtering by use of local statistics," IEEE Transactions on Pattern Analysis and Machine Intelligence, vol. 2, no. 2, pp. 165-168, 1980.

[38] M. Trudel, F. Charbonneau, F. Avendano, and R. Leconte, "Quick Profiler (QuiP): a friendly tool to extract roughness statistical parameters using a needle profiler," Canadian Journal of Remote Sensing, vol. 36, no. 4, pp. 391-396, 2010.

[39] A. G. Voronovich, Wave Scattering from Rough Surfaces, Springer, Heidelberg, Germany, 1994. 
[40] M. C. Dobson, F. T. Ulaby, and M. T. Hallikainen, "Microwave dielectric behavior of wet soil-part II: dielectric mixing models," IEEE Transactions on Geoscience and Remote Sensing, vol. 23, no. 4, pp. 35-46, 1985.

[41] A. K. Fung, Z. Li, and K. S. Chen, "Backscattering from a randomly rough dielectric surface," IEEE Geoscience and Remote Sensing Letters, vol. 30, no. 2, pp. 356-369, 1992.

[42] L. Pasolli, C. Notarnicola, L. Bruzzone et al., "Polarimetric RADARSAT-2 imagery for soil moisture retrieval in alpine areas," Canadian Journal of Remote Sensing, vol. 37, no. 5, pp. 535-547, 2011. 

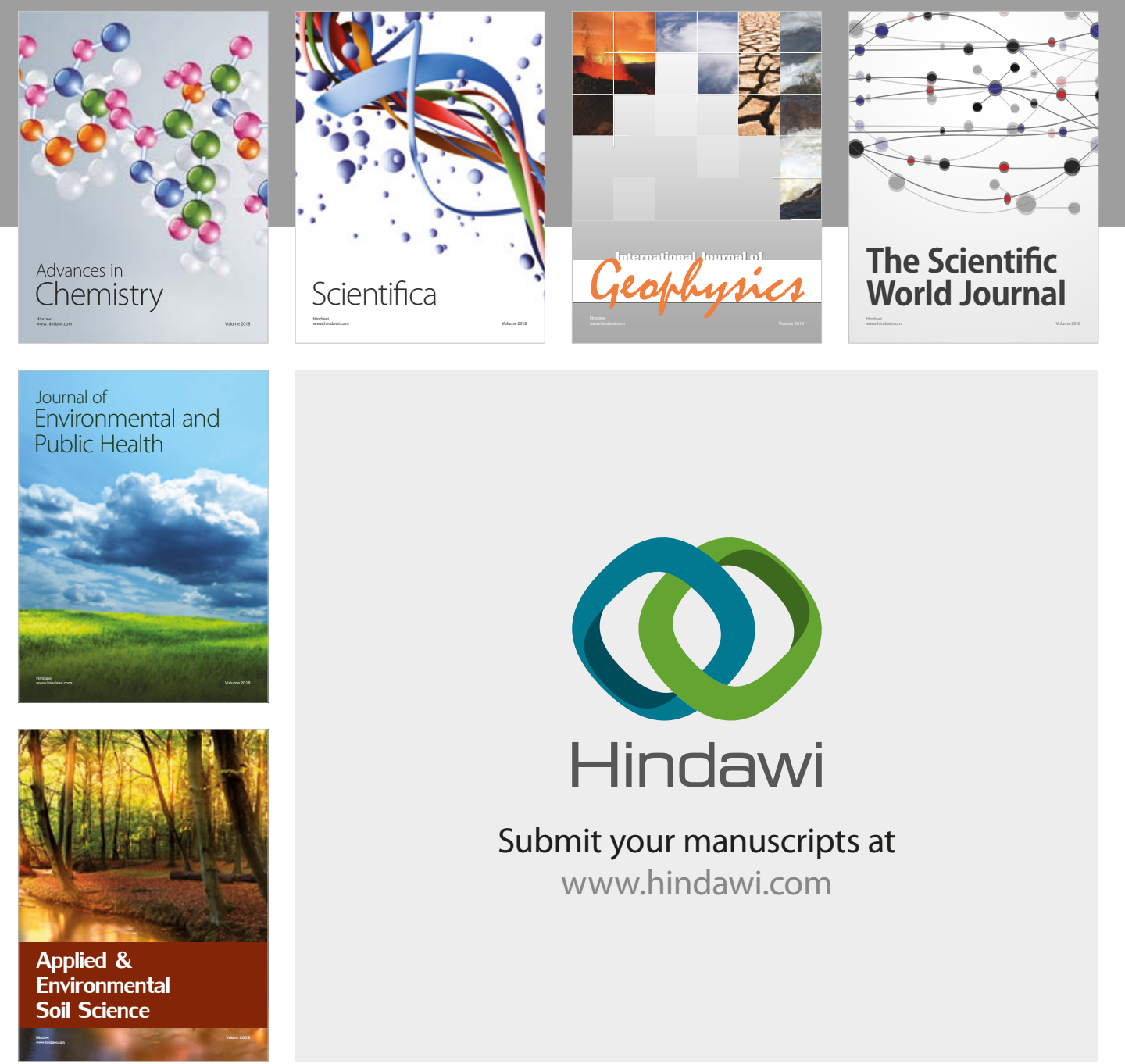

The Scientific

\section{World Journal}
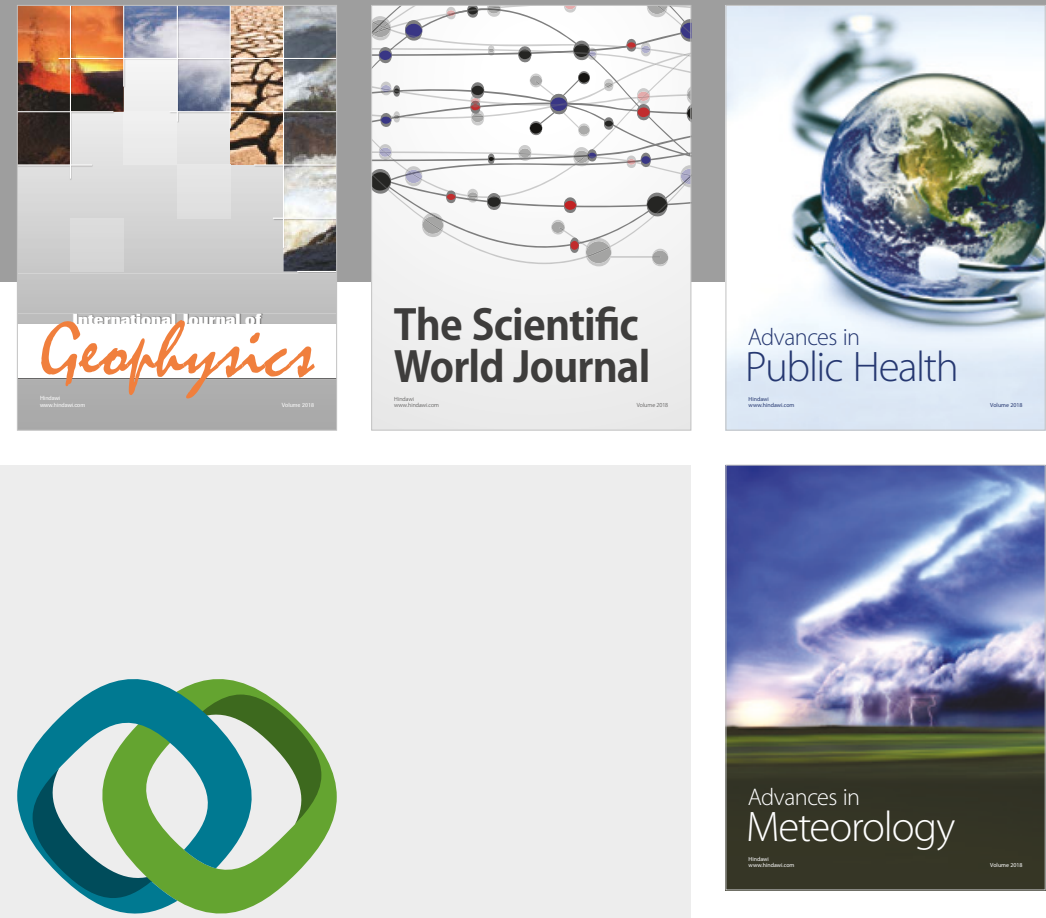

Advan

Public Health

\section{Hindawi}

Submit your manuscripts at

www.hindawi.com
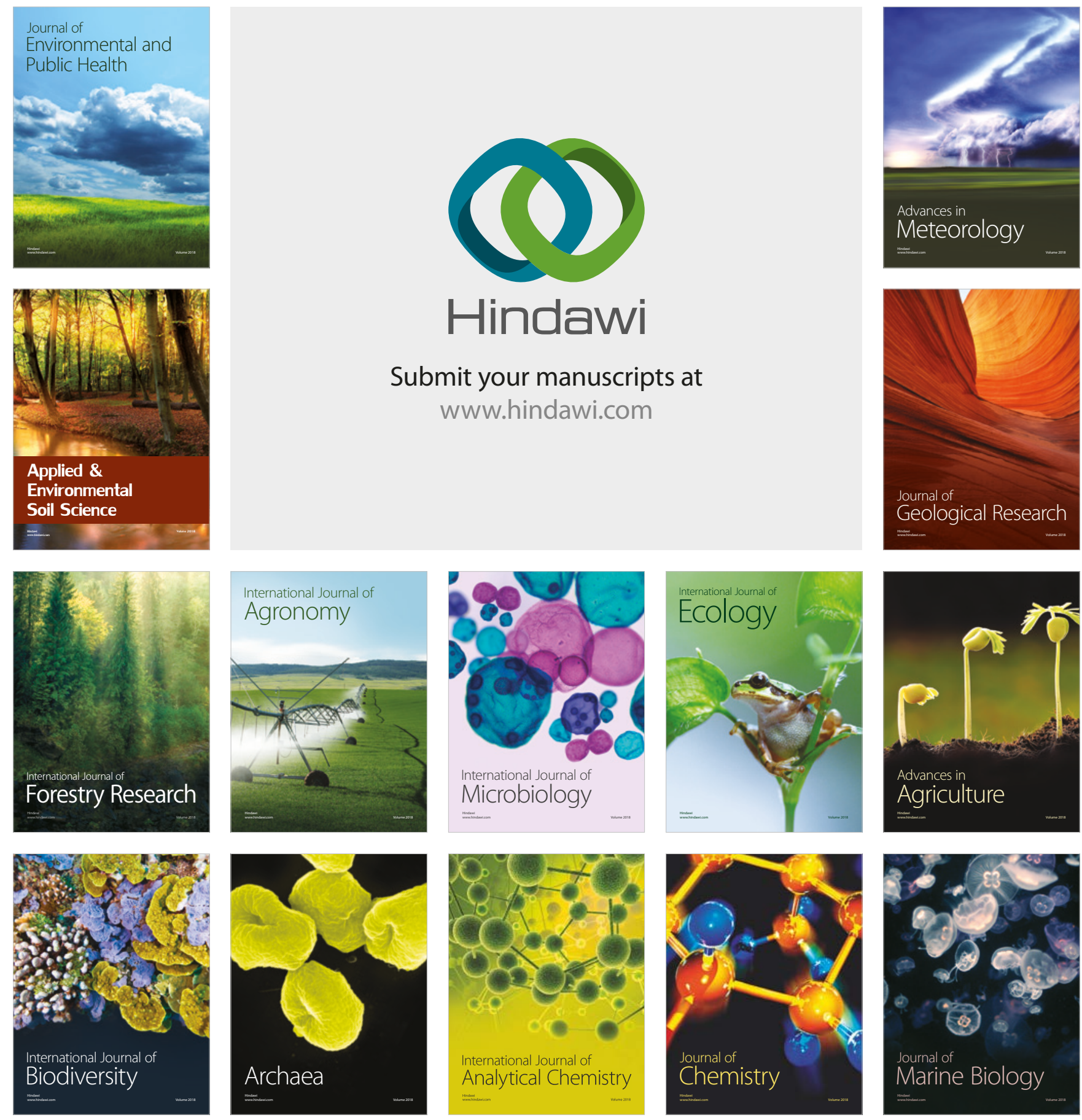